\title{
Intermediacy of Copper(I) under Oxidative Conditions in the Aerobic Copper-Catalyzed Decarboxylative Thiolation of Ben- zoic Acids
}

\author{
Kerry-Ann Green and Jessica M. Hoover* \\ C. Eugene Bennett Department of Chemistry, West Virginia University, Morgantown, West Virginia 26506, United \\ States \\ KEYWORDS: Aerobic, Copper-Catalyzed, Decarboxylative, Thiolation, Mechanistic
}

\begin{abstract}
An experimental mechanistic study of the aerobic copper-catalyzed decarboxylative thiolation of benzoic acids with aryl thiols is reported. For the model reaction, the findings support the corresponding disulfide $(\mathrm{PhSSPh})$ of the aryl thiol $(\mathrm{PhSH})$ as the active thiolating source under reaction conditions. Synthesis and reactivity studies along with kinetic measurements support the chemical and kinetic competence of catalytically active welldefined $\mathrm{Cu}$-complexes; (phen) $\mathrm{Cu}^{\mathrm{I}}\left(\mathrm{O}_{2} \mathrm{CC}_{6} \mathrm{H}_{4}-\mathrm{o}-\mathrm{NO}_{2}\right)(2)$, (phen) $\mathrm{Cu}^{\mathrm{I}}\left(\mathrm{C}_{6} \mathrm{H}_{4}-\mathrm{o}-\mathrm{NO}_{2}\right)(4)$, [(phen) $\left.\mathrm{Cu}^{\mathrm{I}}\left(\mu-\mathrm{SC}_{6} \mathrm{H}_{5}\right)\right]_{2}(3)$ and (phen) $\mathrm{Cu}^{\mathrm{II}}\left(\mathrm{O}_{2} \mathrm{CC}_{6} \mathrm{H}_{4}-\mathrm{O}-\mathrm{NO}_{2}\right)_{2}(5)$, (phen = 1,10-phenanthroline). The presence of an induction period in the stoichiometric reaction of copper(II) complex (phen) $\mathrm{Cu}^{\mathrm{II}}\left(\mathrm{O}_{2} \mathrm{CC}_{6} \mathrm{H}_{4}-\mathrm{o}-\mathrm{NO}_{2}\right)_{2}$ (5) with $\mathrm{PhSSPh}$, and the absence of an induction period in the analogous stoichiometric reaction of copper(I) complex (phen) $\mathrm{Cu}^{\mathrm{I}}\left(\mathrm{O}_{2} \mathrm{CC}_{6} \mathrm{H}_{4}-\mathrm{O}-\mathrm{NO}_{2}\right)(\mathbf{2})$, suggests a copper(I) carboxylate is a more likely intermediate than a copper(II) carboxylate. The observation of in situ reduction of $\mathrm{Cu}^{\mathrm{II}}$ to $\mathrm{Cu}^{\mathrm{I}}$ further supports $\mathrm{Cu}^{\mathrm{I}}$ as the primary active catalytic species and spectroscopic studies also indicate the catalyst resting state to be $\mathrm{Cu}^{\mathrm{I}}$ species. The catalytic reaction exhibits a first order dependence on $\left[\mathrm{Cu}^{\mathrm{I}}\right]$ and $\left[2^{-}\right.$ nitrobenzoic acid] and a zero order dependence on [PhSSPh] and $\mathrm{pO}_{2}$, suggestive of turn-over-limiting decarboxylation of a copper(I) carboxylate. Oxygen was found to promote the essential oxidative cleavage of the copper(I)thiolate intermediate $\left[(\text { phen }) \mathrm{Cu}\left(\mu-\mathrm{SC}_{6} \mathrm{H}_{5}\right)\right]_{2}(3)$ to regenerate a catalytically active $\left[(\mathrm{phen}) \mathrm{Cu}^{\mathrm{II}}\right]\left(\mathrm{Cu}_{\text {ox }}\right)$ species with concomitant formation of $\mathrm{PhSSPh}$. On the basis of these findings, a reaction pathway is proposed for the C-S coupling reaction that includes the key $\mathrm{Cu}^{\mathrm{I}}$-based intermediates, (phen) $\mathrm{Cu}\left(\mathrm{O}_{2} \mathrm{CC}_{6} \mathrm{H}_{4}-\mathrm{o}^{-} \mathrm{NO}_{2}\right)(\mathbf{2})$, and (phen) $\mathrm{Cu}_{(}\left(\mathrm{C}_{6} \mathrm{H}_{4^{-}}\right.$ $\left.o-\mathrm{NO}_{2}\right)(4)$. The pathway accounts for the role of $\mathrm{O}_{2}$ in generating the active thiolating source, $\mathrm{PhSSPh}$, as well as enabling catalytic turnover of in situ generated $\left[(\text { phen }) \mathrm{Cu}\left(\mu-\mathrm{SC}_{6} \mathrm{H}_{5}\right)\right]_{2}(3)$.
\end{abstract}

\section{INTRODUCTION}

Copper-catalyzed cross-coupling reactions are powerful tools for the construction of new C-C and Cheteroatom bonds. ${ }^{1}$ Transition metal-catalyzed decarboxylative cross-coupling reactions offer the advantage of providing high levels of regioselectivity using stable, readily available, simple carboxylic acid substrates. $^{2,3}$ These strategies have been applied extensively to $\mathrm{C}-\mathrm{C}^{4,5}$ and $\mathrm{C}-\mathrm{N}^{6,7}$ bond forming reactions. The corresponding $\mathrm{C}-\mathrm{S}$ coupling reactions, however, are less developed and not well understood mechanistically, ${ }^{8}$ despite the importance of the aryl sulfide motif in pharmaceutically and biologically relevant compounds and as intermediates in organic synthesis. ${ }^{9}$

We recently reported the aerobic copper-catalyzed decarboxylative thiolation of benzoic acids with aryl thiols. ${ }^{10}$ Not only is this system one of the few copper catalysts developed for decarboxylative thiolation reactions," but it is also one of only a handful of oxidative decarboxylative cross-coupling (ODC) reactions capable of employing $\mathrm{O}_{2}$ as the terminal

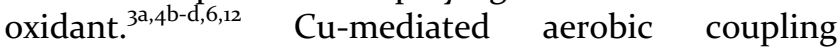
transformations are particularly attractive because of the ubiquitous, cheap and environmentally benign nature of oxygen as oxidant, ${ }^{13-17}$ yet the majority of ODC reactions are plagued by the need for superstoichiometric silver-based oxidants which are known to facilitate the decarboxylation step in many cases. ${ }^{2 a, 18-20}$ An improved understanding of this coppercatalyzed decarboxylative thiolation and related reaction mechanisms could enable the development of more efficient aerobic catalytic copper systems.

Copper-promoted redox-neutral decarboxylative coupling reactions have been studied mechanistically, and the generally accepted pathway for these reactions involves initial decarboxylation of a $\mathrm{Cu}^{\mathrm{I}}$-carboxylate to form a $\mathrm{Cu}^{\mathrm{I}}$-aryl species, followed by activation of the aryl halide or proton-containing coupling partner. ${ }^{5 c, 21-24}$ 
In contrast, the oxidative variants are less well understood, in part due to the various oxidation states accessible to copper. Typical mechanisms proposed for these reactions include decarboxylation from in situ generated $\mathrm{Cu}^{\mathrm{I}}$ - or $\mathrm{Cu}^{\mathrm{II}}$-carboxylates to form the corresponding $\mathrm{Cu}^{\mathrm{I}}$ - or $\mathrm{Cu}^{\mathrm{II}}$-aryl species and subsequent reaction with the nucleophilic coupling partner. Although mechanistic proposals are posited in the literature, ${ }^{4 \mathrm{~d}, 6 \mathrm{a}, 11 \mathrm{a}}$ experimental studies to probe these pathways are limited.

In the case of decarboxylative thiolation reactions, mechanistic proposals are further complicated by the multitude of reaction pathways available to thiols and disulfides under copper-mediated conditions. ${ }^{110,25-28}$ For example, the redox-neutral thiolation of aryl halides has been shown by Hartwig and coworkers $^{29}$ to proceed through activation of the aryl halide by copper(I)-thiolate species, while Ribas and others ${ }^{30}$ have shown an aryl copper(III) pathway to be plausible for the same reaction type (Scheme 1a). Similarly, the $\mathrm{C}\left(\mathrm{sp}^{2}\right)-\mathrm{H}$ thiolation reactions could proceed through either initial $\mathrm{C}-\mathrm{H}$ activation followed by reaction with thiol or disulfide, or initial formation of a copper(I)thiolate which then cleaves the $\mathrm{C}-\mathrm{H}$ bond to form the coupled product (Scheme $\mathrm{lb}$ ). ${ }^{31}$ Thus, for the oxidative decarboxylative thiolation reactions (Scheme 1c), a number of pathways are possible and many mechanistic questions remain.

Scheme 1. Simplified Mechanistic Pathways for Copper-Catalyzed Thiolation Reactions.

(a) Redox-Neutral Thiolation of Aryl Halides

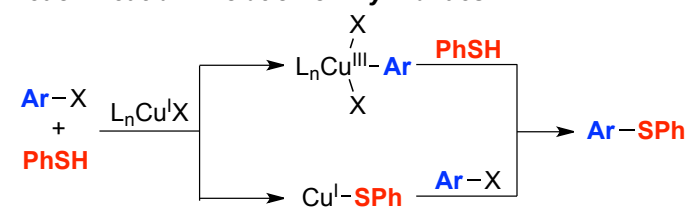

(b) Oxidative $\mathrm{C}-\mathrm{H}$ Thiolation

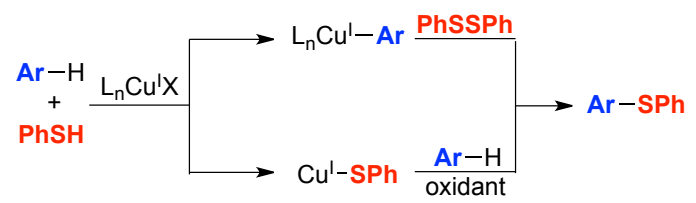

(c) Oxidative Decarboxylative Thiolation

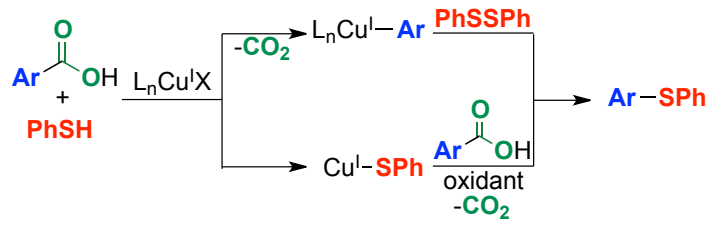

Herein, we report an experimental mechanistic study of the aerobic copper-catalyzed decarboxylative coupling reaction of benzoic acids and aryl thiols to elucidate the nature of the key reactive $\mathrm{Cu}$-based intermediates, identify the active thiolating source and establish the role(s) played by $\mathrm{O}_{2}$. Our findings demonstrate the importance of the disulfide as oxidant and thiolating source; a reactivity pattern that has been acknowledged or observed in related $\mathrm{Cu}$ mediated thiolations. ${ }^{32,33}$ Synthesis and reactivity studies, along with kinetic measurements and spectroscopic studies, support well-defined (phen)Cu ${ }^{\mathrm{I}}$ species as key intermediates and indicate a $\mathrm{Cu}^{\mathrm{I}}$ resting state. A significant role of molecular oxygen is the oxidative dissociation of the in situ generated copper(I)-thiolate dimer to provide disulfide and regenerate a catalytically active $\mathrm{Cu}$ species. These findings of the catalytic relevance of well-defined $\mathrm{Cu}^{\mathrm{I}}$ species under oxidative conditions may have implications for related systems as researchers seek to expand the scope and utility of aerobic $\mathrm{Cu}$-mediated coupling transformations.

\section{RESULTS AND DISCUSSION}

Overview of the Catalytic System. For this mechanistic study, we chose the model reaction of 2nitrobenzoic acid and thiophenol (PhSH), which generates (2-nitrophenyl)(phenyl)sulfane (1) in $84 \%$ yield (Scheme 2). Under the standard catalytic conditions 2-nitrobenzoic acid (6o mM), PhSH (120 $\mathrm{mM}$ ) and potassium carbonate are treated with 10 mol\% of $\mathrm{CuI}$ and $12 \mathrm{~mol} \%$ of 1,10-phenanthroline (phen) in DMSO at $140{ }^{\circ} \mathrm{C}$, under an aerobic atmosphere maintained with an $\mathrm{O}_{2}$ balloon. ${ }^{10}$ The reaction time course can be monitored using an aliquot method with ${ }^{1} \mathrm{H}$ NMR spectroscopic analysis, which shows sharp signals for the sulfide product (1). Monitoring the standard catalytic reaction in this fashion reveals a time course with an approximate 12 min induction period, followed by exponential formation of the product. A linear fit to the early time points following the induction period provides an initial rate of $12.7 \pm 0.6 \mathrm{mM} \mathrm{h}^{-1}$ (Figure S6).

Scheme 2. Model Reaction for Mechanistic Study.

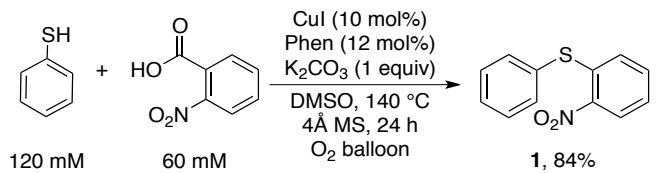

PhSSPh in Catalytic Reactions. The coppermediated oxidation of thiols (RSH) to the corresponding disulfides (RSSR) under aerobic conditions is well established. ${ }^{32,34}$ Furthermore, the intermediacy of RSSR in related oxidative $\mathrm{Cu}$-catalyzed thiolation reactions has been supported by the 
observed formation and demonstrated reactivity of RSSR under typical reaction conditions..$^{32,35}$

Under the standard catalytic decarboxylative thiolation conditions, we observed the nearly quantitative consumption of $\mathrm{PhSH}$ to form $\mathrm{PhSSPh}$ as the only reaction product ( $84 \%$ yield) within the first 4 min of the reaction. Similarly, the CuI/phen-catalyzed aerobic oxidation of $\mathrm{PhSH}$ proceeds rapidly in the absence of 2-nitrobenzoic acid, both with and without $\mathrm{K}_{2} \mathrm{CO}_{3}$. Monitoring this catalytic $\mathrm{PhSH}$ oxidation by ${ }^{1} \mathrm{H}$ NMR spectroscopy provides an estimate of the rate of formation of $\mathrm{PhSSPh}$ in the absence of $\mathrm{K}_{2} \mathrm{CO}_{3}$ as $516 \pm$ $49 \mathrm{mM} \mathrm{h}^{-1}$ at $[\mathrm{PhSH}]_{0}=97 \mathrm{mM}$ (Figure $\mathrm{S}_{7}$ ). Furthermore, when $\mathrm{PhSSPh}$ was employed in place of $\mathrm{PhSH}$ under otherwise standard catalytic decarboxylative thiolation conditions, (2nitrophenyl)(phenyl)sulfane (1) was successfully generated in $82 \%$ yield. ${ }^{10}$ The time course for this reaction in which $[\mathrm{PhSSPh}]_{\mathrm{o}}=60 \mathrm{mM}$ and [2-nitrobenzoic acid $]_{\mathrm{o}}=60 \mathrm{mM}$ shows an initial rate of $13.7 \pm 3.7 \mathrm{mM} \mathrm{h}^{-}$ ${ }^{1}$ (Figures 1 and $\mathrm{S} 9$ ). This reaction rate is within error of that involving PhSH $\left(12.7 \pm 0.6 \mathrm{mM} \mathrm{h}^{-1}\right.$, at $[\mathrm{PhSH}]_{\mathrm{o}}=$ $120 \mathrm{mM}$, vide supra), supporting the chemical and kinetic competence of $\mathrm{PhSSPh}$ as the active thiolating source under standard conditions.

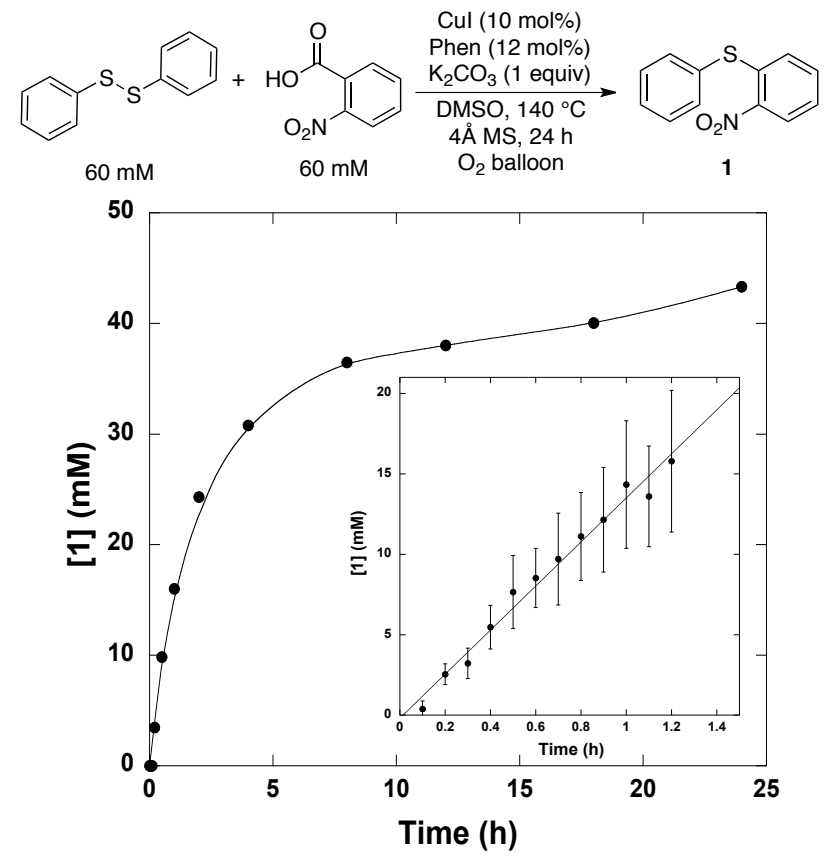

Figure 1. Formation of [(2-nitrophenyl)(phenyl)sulfane] (1) over time for the standard catalytic reaction of 2nitrobenzoic acid with $\mathrm{PhSSPh}$ under $\mathrm{O}_{2}$. The trace of the full time course is not a fit and is included to guide the eye. The inset shows the linear fit to early reaction times; data points are an average of four runs and error bars shown are one standard deviation of the mean.
Identification of a Copper(I) Resting State. The standard catalytic reaction of 2-nitrobenzoic acid with $\mathrm{PhSSPh}$ undergoes characteristic color changes as the reaction progresses. Prior to heating, the reaction mixture is a deep brown color. Upon heating, the mixture turns green initially, followed by a gradual change to yellow-green, and finally a persistent orange-brown color. Because of the observed color changes during the catalytic reactions and the characteristic spectral features in the absorption spectra for $\mathrm{Cu}^{\mathrm{I}}$ and $\mathrm{Cu}^{\mathrm{II}}$ species, UV-visible spectroscopic studies were performed to gain insight into the catalyst resting state.

The UV-visible spectroscopic features of phenanthroline-ligated copper complexes are well established. The low valent (phen) $\mathrm{Cu}^{\mathrm{I}}$ and (phen) ${ }_{2} \mathrm{Cu}^{\mathrm{I}}$ species exist in equilibrium ${ }^{36}$ and give rise to metal-toligand charge transfer absorptions at 364 and $445 \mathrm{~nm}$, respectively. ${ }^{37}$ In contrast, the corresponding (phen) ${ }_{2} \mathrm{Cu}^{\text {II }}$ displays a broad $\mathrm{d}$-d transition band of weak intensity around $700 \mathrm{~nm} .{ }^{38}$ Because the $\sim 364 \mathrm{~nm}$ absorption range is obscured by the sulfane product $\mathbf{1}$ $\left(\lambda_{\max }=375 \mathrm{~nm}\right)$ under our reaction conditions, and given the rapid ligand-exchange equilibria common with phenanthroline-ligated copper(I) species, we will use "(phen)Cu" to refer to both the mono- and bisphenanthroline ligated copper(I) species throughout this study.

The reaction mixture of $\mathrm{CuI}$, phen, $\mathrm{K}_{2} \mathrm{CO}_{3}$, 2nitrobenzoic acid and $\mathrm{PhSSPh}$ was prepared in a septum-sealed cuvette equipped with a stir bar and an $\mathrm{O}_{2}$ balloon, then heated in a pre-heated aluminum block. The reaction mixture has an initial brown color and a strong absorption at $440 \mathrm{~nm}$ characteristic of a (phen) $\mathrm{Cu}^{\mathrm{I}}$ species (Figure 2, black trace) ${ }^{37}$ and a broad band of weak intensity around $699 \mathrm{~nm}$ attributed to $\mathrm{Cu}^{\mathrm{II}} .^{38}$ The presence of copper(II) in the initial reaction mixture results from background oxidation of copper(I) under these aerobic conditions. The band at 440 $\mathrm{nm}$ is suggestive of the formation of (phen)Cu. Upon heating at $140{ }^{\circ} \mathrm{C}$, the spectral band at $440 \mathrm{~nm}$ is quenched (Figure 2, blue trace) followed by the gradual appearance of a new band at $443 \mathrm{~nm}$ (Figure 2, red trace). The appearance of this band was accompanied by the loss of the $\mathrm{Cu}^{\mathrm{II}}$ feature at $699 \mathrm{~nm}$. The behavior observed in the visible region of the spectrum supports a phenanthroline-ligated copper(I), (phen) $\mathrm{Cu}^{\mathrm{I}}$, species as the catalyst resting state, and suggests the initial formation and consumption of a copper(II) species. 

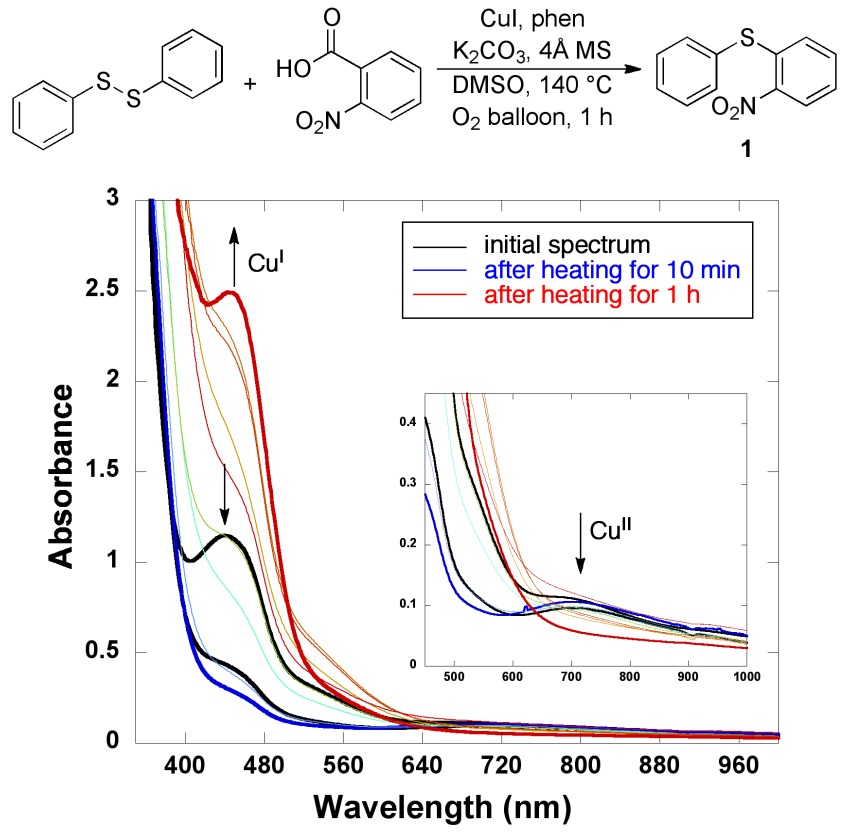

Figure 2. Selected UV-visible spectra measured for the standard catalytic reaction over $\mathbf{l}$ h. Reaction conditions: 2nitrobenzoic acid (9.3 mM), PhSSPh (9.7 mM), CuI (1.1 mM), phen (1.0 mM), $\mathrm{K}_{2} \mathrm{CO}_{3}$ (1.2 equiv), DMSO (2.5 mL), $\mathrm{O}_{2}$ balloon, $140{ }^{\circ} \mathrm{C}$. Final spectrum: from a 3 -fold dilution of the mixture after $1 \mathrm{~h}$.

Determination of Kinetic Reaction Orders. The kinetic dependence of reaction components were measured using an aliquot method. Initial rate measurements reveal a first order dependence on both $[\mathrm{CuI} / \mathrm{phen}]\left([\mathrm{Cu}]_{\mathrm{o}}=3-60 \mathrm{mM}\right.$, Figure $\left.3 \mathrm{a}\right)$ and $[2-$ nitrobenzoic acid] ([2-nitrobenzoic acid $]_{0}=30-120$ $\mathrm{mM}$, Figure $3 \mathrm{~b}$ ), and a zero order dependence on $[\mathrm{PhSSPh}]\left([\mathrm{PhSSPh}]_{\mathrm{o}}=10-120 \mathrm{mM}\right.$, Figure $\left.3 \mathrm{c}\right)$. The observed dependence are suggestive of a turn-overlimiting step that involves a copper carboxylate species. Given the high temperatures and forcing reaction conditions often required for the decarboxylation of copper carboxylates, ${ }^{2 \mathrm{~b}, 23,39-41}$ it is plausible that decarboxylation from such a species could be turn-overlimiting, however formation of a copper(I)-carboxylate, or oxidation of such a species may also be turn-overlimiting.

The possibility of turn-over-limiting oxidation by $\mathrm{O}_{2}$ was explored by measuring the rate of the standard catalytic reaction conducted under air $\left(\sim 21 \% \mathrm{O}_{2}\right)$ used in place of $\mathrm{O}_{2}\left(14.9 \pm 1.8 \mathrm{mM} \mathrm{h}^{-1}\right.$, Figure $\left.\mathrm{S}_{13}\right)$. The data show no dependence on $p \mathrm{O}_{2}$ and instead, indicate a turn-over-limiting-step that is either formation of or decarboxylation from a copper(I)-carboxylate.

Given the observed kinetic dependence, the rate constant for the standard catalytic reaction is determined to be $k=0.038 \pm 0.010 \mathrm{mM}^{-1} \mathrm{~h}^{-1}$. An induction period is observed under some conditions, that appears to correlate with steps that generate an active $\mathrm{Cu}^{\mathrm{I}}$-benzoate species. Although there is no significant induction period under standard catalytic conditions (Figure 1), an induction period of $\sim 12 \mathrm{~min}$ is observed at low [CuI/phen], consistent with the formation of an active copper(I) species during the induction period. The events occurring during this time include copper oxidation and reduction events (vide infra), as well as formation of the copperbenzoate species from copper, the benzoic acid, and base. Thus, to gain further insight into the product forming steps from copper carboxylate species, we sought to explore the reactivity of well-defined copper complexes as described below.
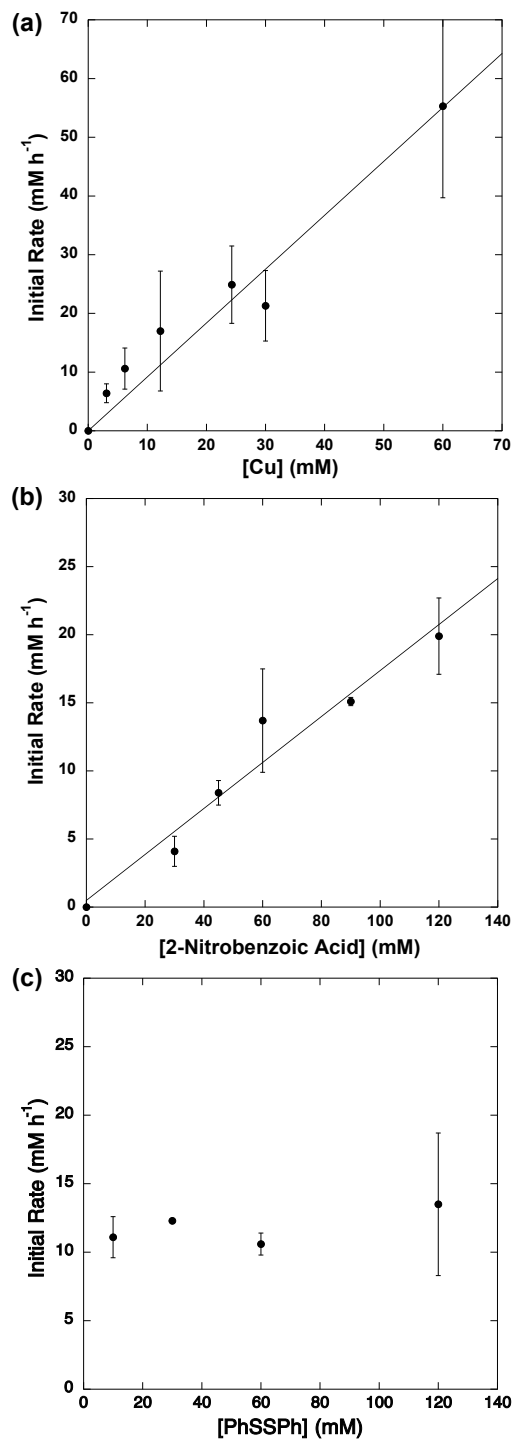

Figure 3. Plot of initial rate $\left(\mathrm{mM} \mathrm{h}^{-1}\right)$ versus $(\mathrm{a})[\mathrm{Cu}](\mathrm{mM})$, (b) [2-nitrobenzoic acid] (mM), and (c) [PhSSPh] (mM) for the standard catalytic reaction of 2-nitrobenzoic acid with $\mathrm{PhSSPh}$ under $\mathrm{O}_{2}$. Data points are an average of two runs and error bars shown are one standard deviation of the mean. 
Intermediacy of Copper(I) Benzoate. Copper(I) benzoate species have been proposed by us and others as key intermediates in decarboxylative coupling reactions ${ }^{4 a, 11 a, 21,40,42}$ and we envisioned (phen) $\mathrm{Cu}\left(\mathrm{O}_{2} \mathrm{CC}_{6} \mathrm{H}_{4}-\mathrm{o}-\mathrm{NO}_{2}\right)(2)$, as a likely species to be generated under our reaction conditions. Therefore, we sought to probe the formation of such a species under typical reaction conditions. The stoichiometric reaction of $\mathrm{CuI}$, phen, 2-nitrobenzoic acid and $\mathrm{K}_{2} \mathrm{CO}_{3}$ in DMSO- $d_{6}$ under $\mathrm{N}_{2}$ at $80^{\circ} \mathrm{C}$ was monitored by in situ ${ }^{1} \mathrm{H}$ NMR analysis (Figure S2). Under these conditions, we observed the formation of $\mathbf{2}$ in approximately $57 \%$ yield after $6 \mathrm{~h}$. The reaction was conducted at $80^{\circ} \mathrm{C}$, because complex 2 is reactive at the typical $140{ }^{\circ} \mathrm{C}$ reaction temperature (vide infra). The identity of 2 was verified by comparison with an authentic sample synthesized according to a literature procedure. ${ }^{4 a}$ This result provides support for the likely generation of $\mathbf{2}$ under the standard reaction conditions. Furthermore, the relatively slow formation of 2 under these conditions is consistent with the generation of this species contributing to the induction period under catalytic conditions (vide supra).

Complex $\mathbf{2}$ is also catalytically competent. The reaction of 2-nitrobenzoic acid and $\mathrm{PhSH}$ with 10 mol\% of complex 2 provided (2nitrophenyl)(phenyl)sulfane (1) in $89 \%$ yield. Similarly, the stoichiometric reaction of $\mathbf{2}$ and PhSSPh in DMSO performed under oxygen furnished 1 in $72 \%$ yield, while the analogous reaction performed under nitrogen provided $\mathbf{1}$ in $75 \%$ yield (Scheme 3 ).

\section{Scheme 3. Stoichiometric Reactions of Complex 2} with PhSSPh under $\mathrm{O}_{2}$ and $\mathrm{N}_{2}$ Atmospheres.

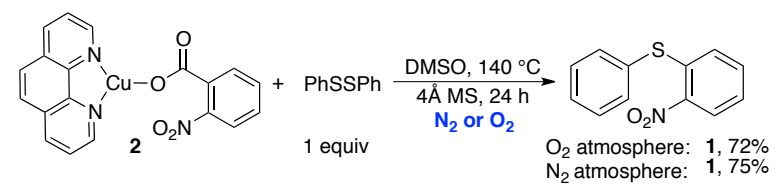

${ }^{1} \mathrm{H}$ NMR analysis of the stoichiometric reaction of 2 with $\mathrm{PhSSPh}$ in DMSO- $d_{6}$ under $\mathrm{N}_{2}$ shows the copper(I)-thiolate dimer $\left[(\text { phen }) \mathrm{Cu}\left(\mu-\mathrm{SC}_{6} \mathrm{H}_{5}\right)\right]_{2}$ (3) to be the sole copper-containing product in $84 \%$ yield (Figure 4a). The identity of 3 was verified following the independent synthesis of this complex from a literature protocol. $^{29}$ The initial rate of this stoichiometric reaction under $\mathrm{N}_{2}$ was determined to be $350.0 \pm 30 \mathrm{mM} \mathrm{h}^{-1}\left(\right.$ at $[2]_{0}=60 \mathrm{mM}$ and $[\mathrm{PhSSPh}]_{\mathrm{o}}=60$ $\mathrm{mM}$, Figures $4 \mathrm{~b}$ and $\mathrm{S} 15$ ), slightly faster but of the same order of magnitude as the rate predicted based on the catalytic reaction rate $\left(13.7 \mathrm{mM} \mathrm{h}^{-1}\right.$ at $\left.6 \mathrm{mM} \mathrm{Cu}\right)$ and the measured first order dependence on [CuI/phen]. In addition, no induction period was observed for this reaction, and the mixture maintained an intense brown to red-brown color throughout, indicative of (phen)Cu${ }^{I}$. These data combined suggest that $\mathbf{2}$ is kinetically competent under reaction conditions and is likely a key reaction intermediate.
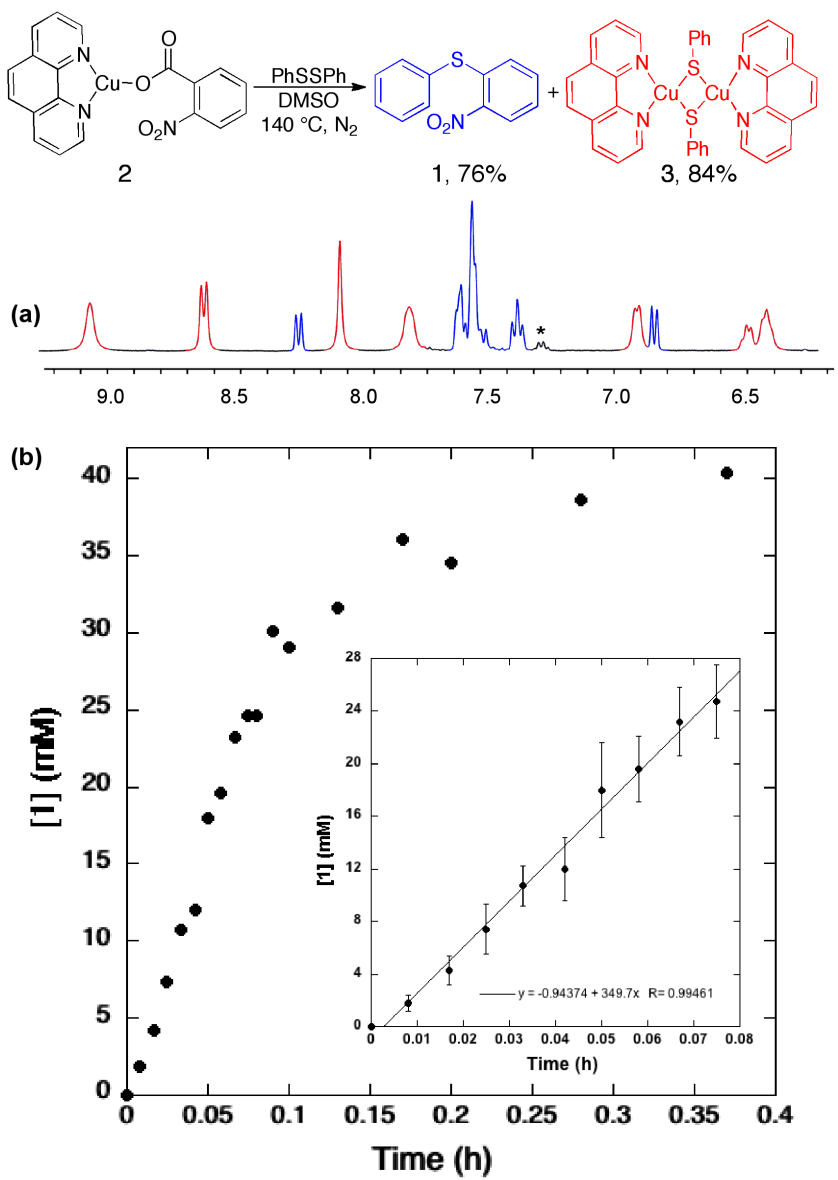

Figure 4. (a) Final ${ }^{1} \mathrm{H}$ NMR spectrum of the reaction of (phen) $\mathrm{Cu}\left(\mathrm{O}_{2} \mathrm{CC}_{6} \mathrm{H}_{4}-\mathrm{O}-\mathrm{NO}_{2}\right)$ (2) (12.7 $\left.\mu \mathrm{mol}, 25.4 \mathrm{mM}\right)$ and $\mathrm{PhSSPh}(12.4 \mu \mathrm{mol}, 24.8 \mathrm{mM})$ under $\mathrm{N}_{2}$ after heating at 140 ${ }^{\circ} \mathrm{C}$ for $55 \mathrm{~min}$ in DMSO- $d_{6}$. Residual PhSSPh is indicated by * (b) Plot of [(2-nitrophenyl)(phenyl)sulfane] (1) $(\mathrm{mM})$ versus time for the reaction of complex $2(60 \mathrm{mM})$ and PhSSPh (6o $\mathrm{mM}$ ) in DMSO under $\mathrm{N}_{2}$. Inset: Early reaction times indicating the linear fit used to calculate the initial rate. Data points are an average of four runs and error bars shown are one standard deviation of the mean.

Intermediacy of Copper(I) Aryl. The efficient generation of 1 from 2 and PhSSPh described above likely involves a decarboxylation step paired with oxidative addition of $\mathrm{Cu}^{\mathrm{I}}$ to the disulfide. ${ }^{\text {na }}$ Sulfide ligands are known to stabilize high-valent $\mathrm{Cu}^{\mathrm{III}}$ and there are instances wherein disulfides oxidize $\mathrm{Cu}^{\mathrm{I}}$ to $\mathrm{Cu}^{\text {III }}$.43,44 Consequently, discrete organocopper(III) thiolate species have also been proposed as intermediates in oxidative $\mathrm{Cu}$-catalyzed thiolation reactions. ${ }^{110,45}$ Thus we imagined a product-forming pathway involving initial decarboxylation of 2 to 
generate a copper(I)-aryl species capable of undergoing oxidative addition with $\mathrm{PhSSPh}$ (Scheme 4).

\section{Scheme 4. Plausible Pathway for Product For- mation from Complex 2.}

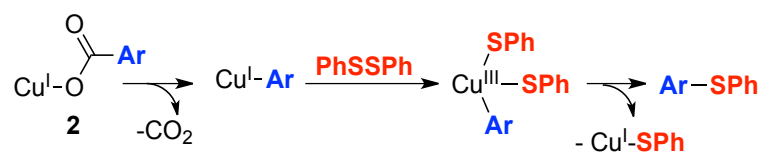

We therefore explored the reactivity of the $\mathrm{Cu}^{\mathrm{I}}$-(aryl) complex (phen) $\mathrm{Cu}\left(\mathrm{C}_{6} \mathrm{H}_{4}-\mathrm{o}-\mathrm{NO}_{2}\right)(4)^{4 \mathrm{a}}$ as a possible reaction intermediate. When a mixture of 2nitrobenzoic acid and $\mathrm{PhSH}$ was treated with $10 \mathrm{~mol} \%$ of 4 under standard catalytic conditions, the (2nitrophenyl)(phenyl)sulfane product (1) was obtained in $75 \%$ yield. On treatment of $\mathbf{4}$ with a stoichiometric amount of PhSSPh (1 equiv) under $\mathrm{O}_{2} 39 \%$ yield of 1 was obtained along with the 2,2'-dinitrobiphenyl byproduct in $12 \%$ (Scheme 5 ). Both an improved yield

Scheme 5. Stoichiometric Reactions of Complex 4 with PhSSPh.

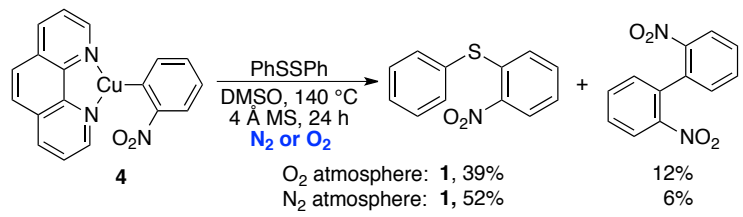

of $1(52 \%)$ and a reduction in byproduct formation (6\%) resulted when the same reaction was conducted under nitrogen. The moderate yields of $\mathbf{1}$ formed from these stoichiometric reactions of 4 at $140{ }^{\circ} \mathrm{C}$ are attributed to the competitive decomposition of 4 at elevated temperatures. In a control experiment at 140 ${ }^{\circ} \mathrm{C}$ in DMSO- $d_{6}$ under $\mathrm{N}_{2}, 4$ was observed to decompose to a mixture containing nitrobenzene and 2,2'dinitrobiphenyl (see SI for details). Therefore, we also explored the stoichiometric reaction of 4 with $\mathrm{PhSSPh}$ under milder room temperature conditions.

The reaction of $\mathbf{4}$ with $\mathrm{PhSSPh}$ was conducted under $\mathrm{N}_{2}$ at room temperature in a J. Young NMR tube. ${ }^{1} \mathrm{H}$ NMR analysis reveals the rapid formation of 1 in $82 \%$ and $\left[(\text { phen }) \mathrm{Cu}\left(\mu-\mathrm{SC}_{6} \mathrm{H}_{5}\right)\right]_{2} \quad$ (3) in $90 \%$ within approximately $7 \mathrm{~min}$ of mixing (Figure 5 ). No other reaction products were observed. Because the reaction is nearly complete within $7 \mathrm{~min}$ at room temperature, we were unable to measure the initial rate for this reaction. Nevertheless, these observations confirm the facile formation of $\mathbf{1}$ from $\mathbf{4}$ and are consistent with the formation of a reactive organocopper(III) dithiolate complex via oxidative addition of PhSSPh to 4 (Scheme 4).
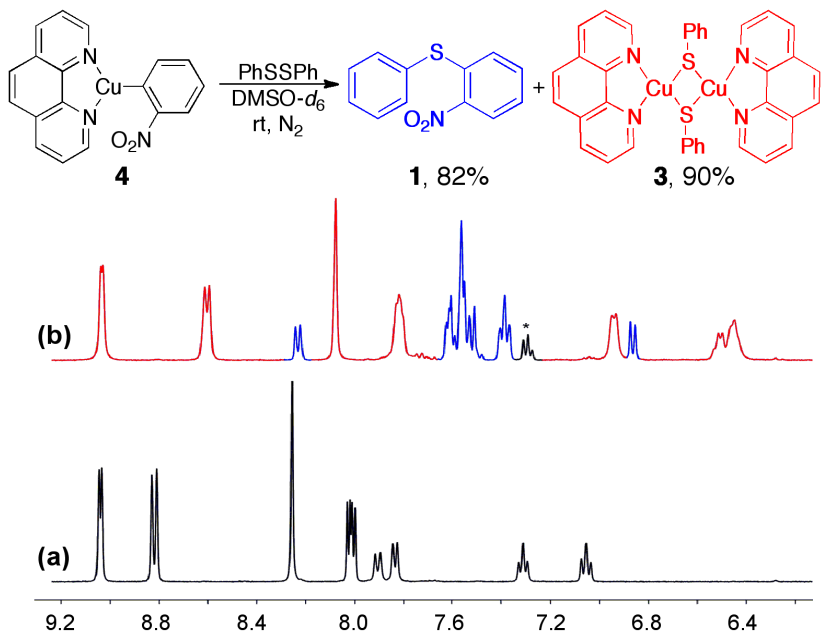

Figure 5. ${ }^{1} \mathrm{H}$ NMR spectra of (a) 4 in DMSO- $d_{6}$ at rt, and (b) a mixture of 4 (12.6 $\mu \mathrm{mol}, 25.2 \mathrm{mM})$ and PhSSPh $(12.8 \mu \mathrm{mol}$, $25.6 \mathrm{mM})$ in DMSO- $d_{6}(0.5 \mathrm{~mL})$ under $\mathrm{N}_{2}$ after 7 min at rt. Products: (2-nitrophenyl)(phenyl)sulfane (1) and 3. Residual $\mathrm{PhSSPh}$ is indicated by *.

Synthesis and Reactivity of Copper(II) Benzoate. The observed formation of $\mathrm{Cu}^{\text {II }}$ species at early reaction times by UV-visible spectroscopy (vide supra) suggests that divalent copper species could also be relevant intermediates in these oxidative decarboxylative thiolation reactions. The oxidation of a $\mathrm{Cu}^{\mathrm{II}}$ (aryl) species by a sulfenyl radical $(\cdot \mathrm{SR})$ to generate the corresponding $\mathrm{Cu}^{\mathrm{III}}($ aryl)(SR) species has been proposed in related systems and is a possible pathway under our reaction conditions. ${ }^{46}$ Additionally, we and others have shown $\mathrm{Cu}^{\mathrm{II}}$ benzoate species to be likely intermediates in decarboxylative arylation $^{4 \mathrm{a}}$ and selenation reactions. ${ }^{47}$ Consequently, the copper(II) complex (phen) $\mathrm{Cu}\left(\mathrm{O}_{2} \mathrm{CC}_{6} \mathrm{H}_{4}-\mathrm{o}-\mathrm{NO}_{2}\right)_{2}$ (5) was prepared, ${ }^{4 \mathrm{a}}$ and its reactivity probed. Complex 5 was catalytically competent for the model reaction of 2nitrobenzoic acid with $\mathrm{PhSH}$ and generated (2nitrophenyl)(phenyl)sulfane (1) in $98 \%$ yield. We also probed the stoichiometric reaction of $\mathbf{5}$ with $\mathrm{PhSSPh}$ and observed the successful generation of 1 in $74 \%$ yield under oxygen, and $76 \%$ under nitrogen (based on carboxylate, Scheme 6).

Scheme 6. Stoichiometric Reactions of Complex 5 with PhSSPh

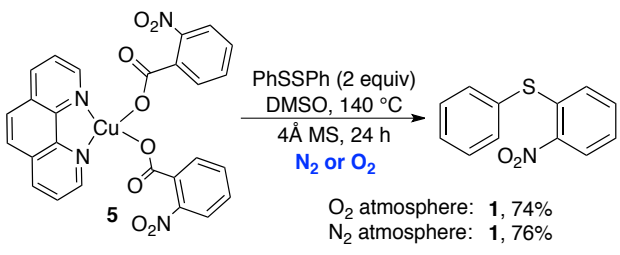

When this stoichiometric reaction was conducted under an air atmosphere in DMSO- $d_{6}$ no copper- 
containing species could be observed by ${ }^{1} \mathrm{H}$ NMR spectroscopy at the end of the reaction. In contrast, when the same stoichiometric reaction was conducted under $\mathrm{N}_{2}, \quad\left[(\text { phen }) \mathrm{Cu}\left(\mu-\mathrm{SC}_{6} \mathrm{H}_{5}\right)\right]_{2} \quad$ (3) was formed quantitatively as the only copper-containing product (Figure 6). In addition, the (2nitrophenyl)(phenyl)sulfane (1) is formed quantitatively and exclusively. Two equivalents of $\mathbf{1}$ are formed for each equivalent of $\mathbf{5}$ indicating that both carboxylates of $\mathbf{5}$ are consumed to generate product with the reduction of $\mathrm{Cu}^{\mathrm{II}}$ to $\mathrm{Cu}^{\mathrm{I}}$.

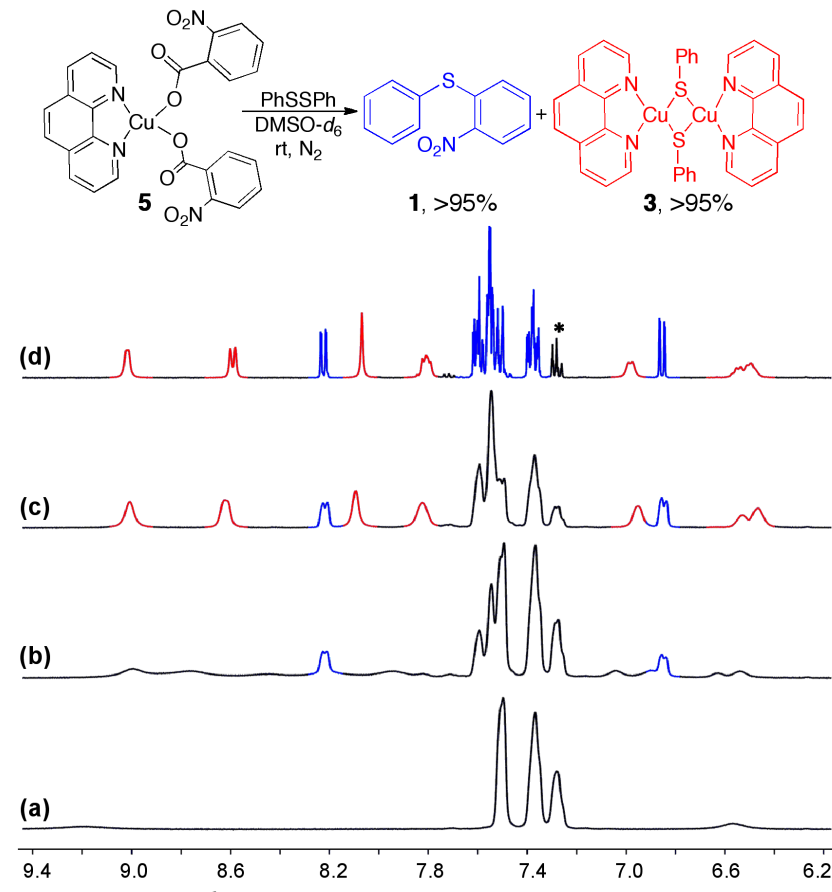

Figure 6. ${ }^{1} \mathrm{H}$ NMR spectra of the reaction of (phen) $\mathrm{Cu}\left(\mathrm{O}_{2} \mathrm{CC}_{6} \mathrm{H}_{4}-\mathrm{O}-\mathrm{NO}_{2}\right)_{2}$ (5) (6.1 $\mu \mathrm{mol}$, $\left.10.2 \mathrm{mM}\right)$ and PhSSPh (12.4 $\mu \mathrm{mol}, 20.7 \mathrm{mM})$ in DMSO- $d_{6}$ (o.6 mL) under $\mathrm{N}_{2}$. (a) mixture of 5 and PhSSPh in DMSO- $d_{6}$ at rt (b) mixture heated at $140{ }^{\circ} \mathrm{C}$ for $9 \mathrm{~min}$ (c) mixture heated at $140{ }^{\circ} \mathrm{C}$ for 40 min (d) mixture heated at $140{ }^{\circ} \mathrm{C}$ for $3 \mathrm{~h} 40 \mathrm{~min}$. Residual $\mathrm{PhSSPh}$ is indicated by *.

The reduction of $\mathrm{Cu}^{\mathrm{II}}$ to $\mathrm{Cu}^{\mathrm{I}}$ in the stoichiometric reaction of $\mathbf{5}$ with $\mathrm{PhSSPh}$ is supported by $\mathrm{UV}$-visible spectroscopic experiments. Upon heating complex $\mathbf{5}$ and $\mathrm{PhSSPh}$ in DMSO at $140{ }^{\circ} \mathrm{C}$ under $\mathrm{N}_{2}$ the absorbances at $\sim 438 \mathrm{~nm}$ and $535 \mathrm{~nm}$ grow in over time, diagnostic of (phen)Cu (Figure 7). Concurrently, there is a loss of the broad band at $\sim 695 \mathrm{~nm}$, typical of $\mathbf{5}$. These observations indicate the generation of $\mathrm{Cu}^{\mathrm{I}}$ during this reaction and support its relevance under reaction conditions.

Finally, monitoring the stoichiometric reaction under $\mathrm{N}_{2}$ by ${ }^{1} \mathrm{H}$ NMR spectroscopy of reaction aliquots allows us to probe the kinetic behavior of the reaction. For the reaction in which $[5]_{0}=30 \mathrm{mM}$ and $[\mathrm{PhSSPh}]_{0}=$ 6o $\mathrm{mM}$ the formation of product $\mathbf{1}$ produces an apparent sigmoidal curve with an approximate $3 \mathrm{~min}$ induction period (Figure 8, red points). Qualitative observations of the reaction of 5 with $\mathrm{PhSSPh}$ also support the reduction of copper(II) to copper(I) during the initial lag phase. Visual observation reveals that upon heating, the blue color characteristic of 5 dissipates and the mixture becomes green. After the approximate 3 minute induction period, the mixture becomes yellow-green, followed by a rapid change to a final persistent orange-brown color indicative of $\mathrm{Cu}^{\mathrm{I}}$.

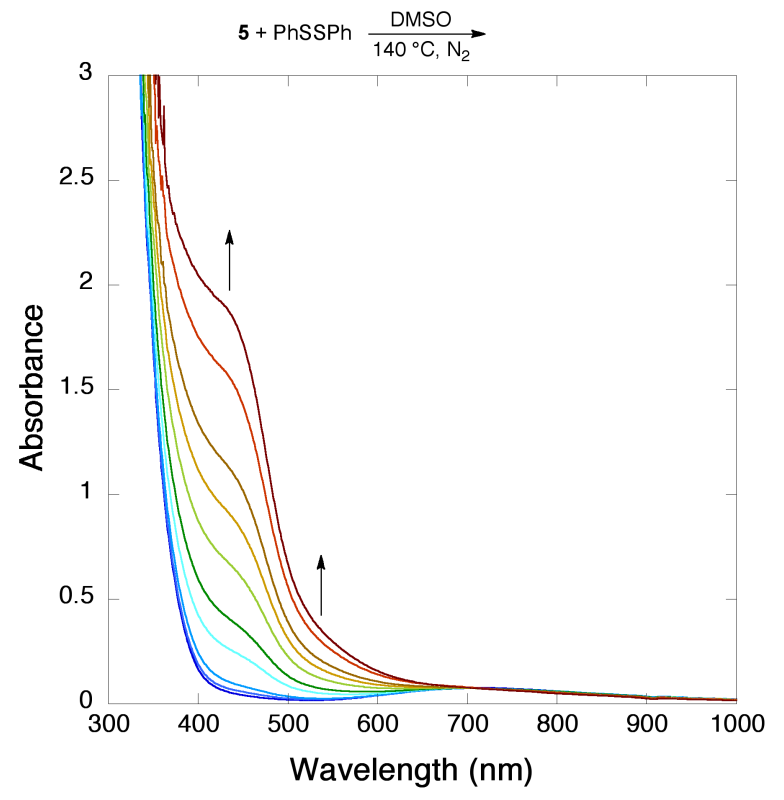

Figure 7. UV-visible spectra for the stoichiometric reaction of 5 and $\mathrm{PhSSPh}$ under $\mathrm{N}_{2}$ at $140{ }^{\circ} \mathrm{C}$ in DMSO. Reaction conditions: (phen) $\mathrm{Cu}\left(\mathrm{O}_{2} \mathrm{CC}_{6} \mathrm{H}_{4}-\mathrm{O}-\mathrm{NO}_{2}\right)_{2}$ (5) (o.83 mM), PhSSPh (1.6 mM), DMSO (2.5 mL), $\mathrm{N}_{2}$ balloon, $140^{\circ} \mathrm{C}$.

The presence of an induction period and sigmoidal time course for the reaction of complex 5 with $\mathrm{PhSSPh}$ is in contrast to the observations for the copper(I) complex 2, for which no induction period was observed (vide supra). A comparison of the reaction time courses for the stoichiometric reactions of complexes $\mathbf{2}$ and $\mathbf{5}$ with $\mathrm{PhSSPh}$ under $\mathrm{N}_{2}$ at $140{ }^{\circ} \mathrm{C}$, obtained by ${ }^{1} \mathrm{H}$ NMR analysis of reaction aliquots is represented in Figure 8. Despite the difference in appearance of the two time courses, both reactions form 1 and complex 3 in high yields and as the sole reaction products.

The empirical observations combined with the lack of an induction period in the case of 2 and the presence of $\mathrm{a} \sim 3 \mathrm{~min}$ induction period in the case of 5 serve to corroborate the intermediacy of the $\mathrm{Cu}^{\mathrm{I}}$ species and suggest reduction of $\mathrm{Cu}^{\mathrm{II}}$ to $\mathrm{Cu}^{\mathrm{I}}$ during the initial slow phase. Additionally, the observed similarity in reaction products for the reactions of 2 and 5 with $\mathrm{PhSSPh}$ is consistent with $\mathrm{Cu}^{\mathrm{I}}$ and $\mathrm{Cu}^{\mathrm{II}}$ complexes generating product via a common pathway. Thus, these data indicate that direct decarboxylation from a 
copper(II) benzoate intermediate is unlikely, and instead reduction to copper(I) and subsequent decarboxylative coupling from a copper(I) carboxylate is more plausible.
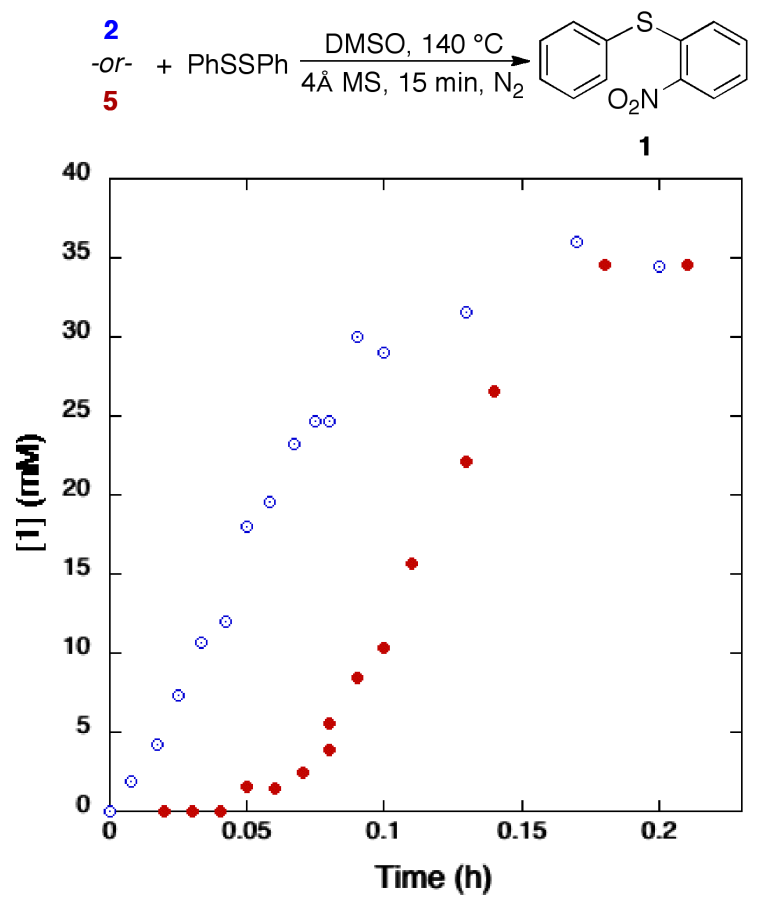

Figure 8. Comparison of reaction profiles for the reaction of (phen) $\mathrm{Cu}\left(\mathrm{O}_{2} \mathrm{CC}_{6} \mathrm{H}_{4}-\mathrm{o}-\mathrm{NO}_{2}\right) \quad$ (2) (6o $\left.\quad \mathrm{mM}\right) \quad \odot$, and (phen) $\mathrm{Cu}\left(\mathrm{O}_{2} \mathrm{CC}_{6} \mathrm{H}_{4}-\mathrm{O}-\mathrm{NO}_{2}\right)_{2}(5)$ (3o mM) 0 , with PhSSPh (6o $\mathrm{mM}$ ) under $\mathrm{N}_{2}$ at $140{ }^{\circ} \mathrm{C}$. Product concentrations were determined by quantitative ${ }^{1} \mathrm{H}$ NMR analysis.

Decarboxylation of Copper(II) Benzoate. In the absence of $\mathrm{PhSSPh}$, the reduction of $\mathrm{Cu}^{\mathrm{II}}$ complex 5 occurs via a distinct, decarboxylation-based pathway to generate 2 and 2,2'-dinitrobiphenyl as the oxidation product (Scheme 7 ). The ${ }^{1} \mathrm{H}$ NMR spectrum of complex 5 in DMSO- $d_{6}$ at rt under $\mathrm{N}_{2}$ is broad and almost featureless. Upon heating at $140{ }^{\circ} \mathrm{C}$, a gradual sharpening of the signals occurs along with the formation of nitrobenzene and 2,2'-dinitrobiphenyl. These changes in the ${ }^{1} \mathrm{H}$ NMR spectra are accompanied by a change in the color of the initially blue solution of 5 to a final orange-brown color indicative of $\mathrm{Cu}^{\mathrm{I}}$ formation.

Scheme 7. Proposed pathway for the reduction of 5 under $\mathrm{N}_{2}$ in the absence of PhSSPh.

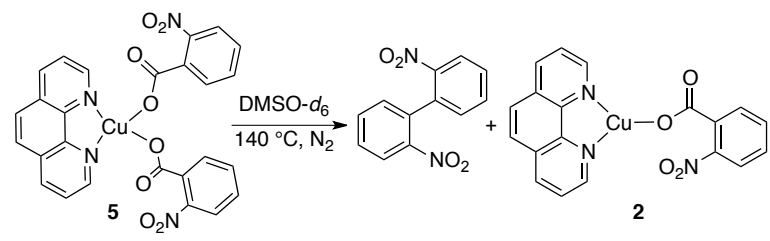

Probing the same decarboxylation of 5 by UV-visible spectroscopy, reveals the loss of the initial band at 695 nm characteristic of $\mathbf{5}$ with the formation of a new band at $444 \mathrm{~nm}$ and an additional increase in absorption at $\sim 543 \mathrm{~nm}$. This final spectrum is identical to the spectrum of 2 (Figure S26). The spectroscopic data suggest that a decarboxylation pathway could be responsible for the initial reduction of $\mathrm{Cu}^{\mathrm{II}}$ to $\mathrm{Cu}^{\mathrm{I}}$.

Reduction of $\mathrm{Cu}^{\mathrm{II}}$ to $\mathrm{Cu}^{\mathrm{I}}$ prior to decarboxylation is consistent with work by Cohen et al. ${ }^{39}$ who showed $\mathrm{Cu}^{\mathrm{I}}$ to be the active catalyst in the decarboxylation of cupric aromatic carboxylates in quinoline solvent. Evidence for the reduction of $\mathrm{Cu}^{\mathrm{II}}$ to $\mathrm{Cu}^{\mathrm{I}}$ in this prior work was provided by the loss of the ESR signal within a few minutes, prior to decarboxylation. In addition, the observed $\mathrm{Cu}^{\mathrm{II}}$-(2-nitrobenzoate) was found to decarboxylate 100 times slower than its $\mathrm{Cu}^{\mathrm{I}}$ counterpart. $^{22}$ In these cases, the reduction of $\mathrm{Cu}^{\mathrm{II}}$ to $\mathrm{Cu}^{\mathrm{I}}$ was attributed to the capability of the quinoline to facilitate the conversion, via the possible formation of 2-oxygenated quinolines. ${ }^{39}$

The reduction of $\mathrm{Cu}^{\mathrm{II}}$ to $\mathrm{Cu}^{\mathrm{I}}$ in the absence of an explicit reductant has been observed throughout the realm of copper-mediated transformations. ${ }^{48,49}$ For example, in the related Ullmann-type coupling to form $\mathrm{C}-\mathrm{O}$ and $\mathrm{C}-\mathrm{N}$ bonds, ${ }^{50,51}$ Paine $^{48 \mathrm{a}}$ and Weingarten ${ }^{51}$ observed that in the presence of coordinating nucleophiles, $\mathrm{Cu}^{\text {II }}$ reduces to active $\mathrm{Cu}^{\mathrm{I}}$ species prior to catalysis, with the concomitant oxidation of the phenoxide and amine nucleophiles. ${ }^{\text {ib }}$ More recently, Jutand and coworkers ${ }^{37 \mathrm{a}}$ reported on the reduction of phenanthroline-ligated $\mathrm{Cu}^{\mathrm{II}}$ precursors by alcohols or amines to generate the active $\mathrm{Cu}^{\mathrm{I}}$ catalyst in the presence of $\mathrm{Cs}_{2} \mathrm{CO}_{3}$. Peñéñory and coworkers ${ }^{37 \mathrm{~b}}$ later made a similar observation with a sulfur-based nucleophile. Yi and coworkers, ${ }^{48 \mathrm{~b}}$ further reported on the role of the tert-butoxide anion as base and as single electron donor in promoting the reduction of $\mathrm{Cu}^{\text {II }}$ precursors via the homolytic cleavage of an $\mathrm{O}-\mathrm{Cu}^{\mathrm{II}}$ bond. Thus, many pathways have been established for the in situ reduction of $\mathrm{Cu}^{\mathrm{II}}$ to $\mathrm{Cu}^{\mathrm{I}}$, however a unique decarboxylation step appears to be responsible for the reduction of these copper(II)-carboxylate species.

Based on the data above, we expected the reaction shown in Scheme 7 to be responsible for the initial uncatalyzed formation of $\mathbf{2}$ from $\mathbf{5}$ in the stoichiometric reaction of $\mathbf{5}$ with $\mathrm{PhSSPh}$. Alternatively, 2 could also result from an initial step involving the reaction of 5 with PhSSPh (Scheme 8, step 1). Thus, we monitored the stoichiometric reaction of $\mathbf{5}$ with $\mathrm{PhSSPh}$ by ${ }^{1} \mathrm{H}$ NMR spectroscopy at two different initial concentrations of $\mathrm{PhSSPh}$ to help distinguish between these two possible pathways (Figure 9). Under these conditions, there is a clear dependence of the initial lag phase on $[\mathrm{PhSSPh}]_{\mathrm{o}}$ indicating a key role for disulfide in the initial reaction of complex 5. 


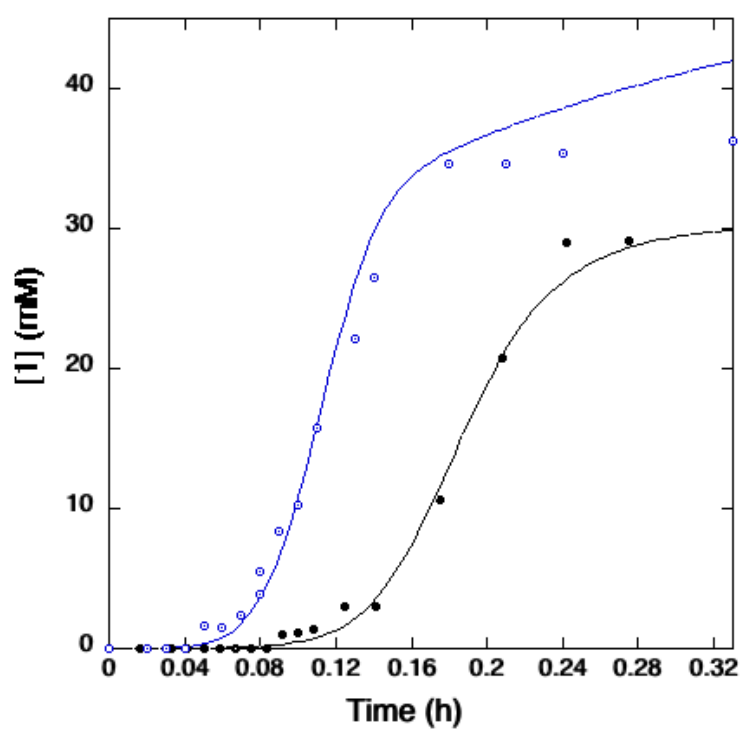

Figure 9. Comparison of reaction profiles for the reaction of (phen) $\mathrm{Cu}\left(\mathrm{O}_{2} \mathrm{CC}_{6} \mathrm{H}_{4}-\mathrm{O}-\mathrm{NO}_{2}\right)_{2}$ (5) (30 mM) with $\mathrm{PhSSPh}$ at 30 $\mathrm{mM}(\odot)$ and $60 \mathrm{mM}(\odot)$ under $\mathrm{N}_{2}$ at $140{ }^{\circ} \mathrm{C}$. Product concentrations were determined by quantitative ${ }^{1} \mathrm{H}$ NMR analysis.

Loss of Induction Period with Complex 3. The time course profiles for the stoichiometric reactions of complex 5 all feature a distinctive sigmoidal shape. Sigmoidal time course traces characterized by this type of three-phase kinetic profile, i.e. a lag, exponential and saturation phase, are common under conditions of autocatalysis, in which a reaction product catalyzes its own formation. ${ }^{52,53}$ Because the stoichiometric reaction of complex 5 with $\mathrm{PhSSPh}$ generates the copper(I)thiolate complex 3, we suspected that complex 3 may catalyze the conversion of $\mathbf{5}$ to product $\mathbf{1}$ with the concomitant formation of complex 2 (Scheme 9). The resulting copper(I)-carboxylate $\mathbf{2}$ also generates product 1 upon reaction with $\mathrm{PhSSPh}$ as shown in Scheme 3 above, leading to the three step sequence shown in Scheme 8. In this sequence, Steps 1 and 3 are identical, with the exception that Step 3 is catalyzed by complex 3.

In this model, Step 2 corresponds to the stoichiometric reaction of complex 2 with $\mathrm{PhSSPh}$, discussed above $\left(k_{2}=0.097 \pm 0.008 \mathrm{mM}^{-1} \mathrm{~h}^{-1}\right)$. The time course data for the reaction of $\mathbf{5}$ with $\mathrm{PhSSPh}(30 \mathrm{mM})$ was fit to this model using the reaction fitting and data simulation software COPASI ${ }^{54}$ The time course data are shown in Figure 9 and the black trace shown is obtained from fitting the experimental data to the model described above. This fit provides rate constants of $k_{1}=0.0010 \pm 0.00045, k_{3}=6.20 \pm 0.63$. This same model and rate constants were then used to predict the time course for the reaction of 2 with $\mathrm{PhSSPh}$ (6o mM, blue trace). Both data sets are well described by the same model. It is worth noting that this and all stoi- chiometric reactions of $\mathbf{5}$ feature increased scatter in the data at later reactions times, likely due to competing side reactions and decomposition pathways (Figures $\mathrm{S}_{16}$ and $\mathrm{S}_{17}$ ).

Scheme 8. Proposed Pathway for the Reaction of 5 with $\mathrm{PhSSPh}$ under $\mathrm{N}_{2}$.

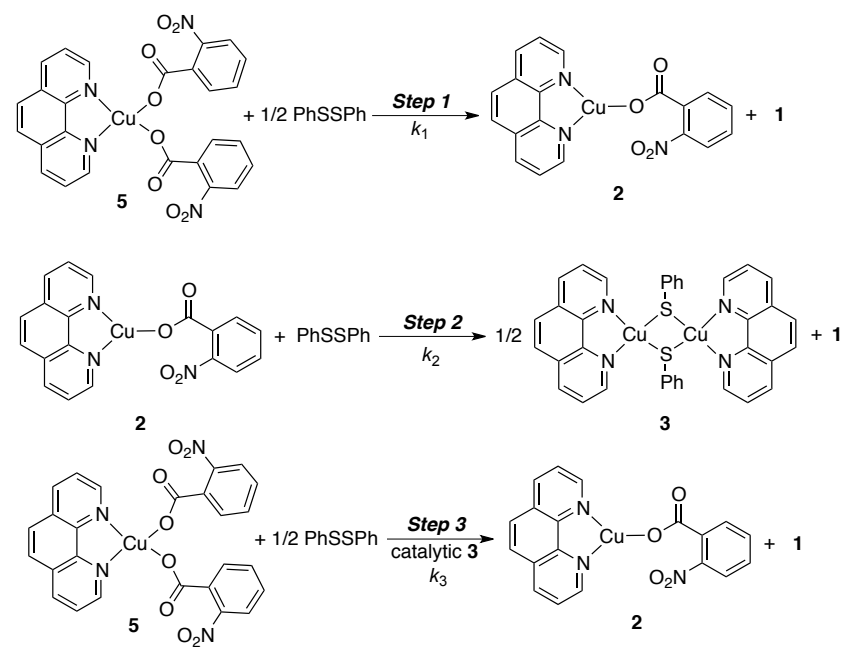

To directly probe the possible catalysis by 3 , the inclusion of a small amount of 3 (0.05 or 0.1 equiv) at the beginning of the reaction of $\mathbf{5}$ with $\mathrm{PhSSPh}$ led to the disappearance of the induction period (Figure 10). Variable time normalization analysis (VTNA) of these time course data with the graphical evaluation method developed by Burés and coworkers ${ }^{55}$ (Figure S18b) indicates a 0.5 order dependence on [3], indicative of dissociation of this dimeric complex to access the reactive monomeric form, (phen) $\mathrm{Cu}(\mathrm{SPh})$. These time course

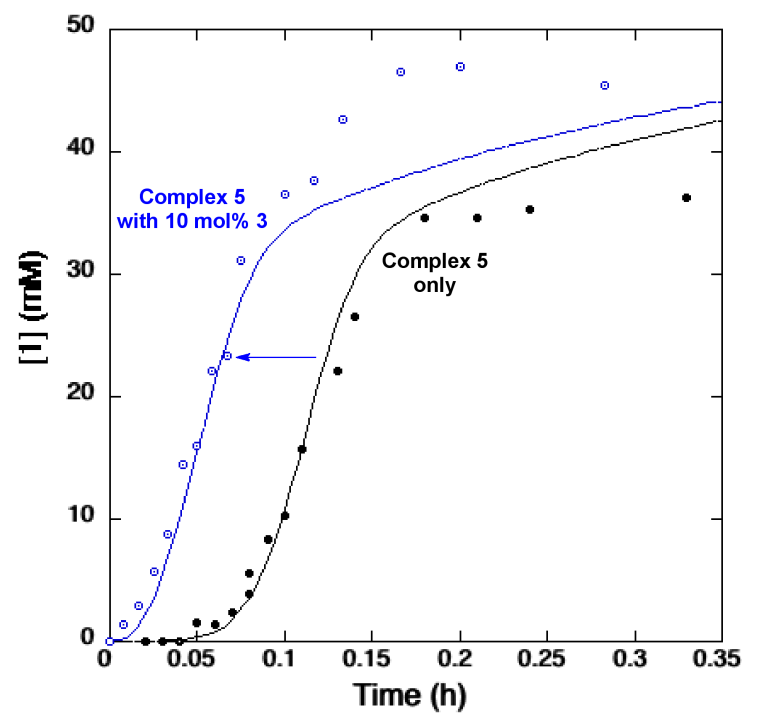

Figure 1o. Comparison of the reaction profiles for the reaction of (phen) $\mathrm{Cu}\left(\mathrm{O}_{2} \mathrm{CC}_{6} \mathrm{H}_{4}-\mathrm{o}-\mathrm{NO}_{2}\right)_{2}$ (5) (30 mM) with $\mathrm{PhSSPh}$ (6o mM) under $\mathrm{N}_{2}$ at $140{ }^{\circ} \mathrm{C}$ with $(\odot)$ and without $(\bullet)$ complex $3(3 \mathrm{mM})$. Product concentrations were determined by quantitative ${ }^{1} \mathrm{H}$ NMR analysis. 
data can also be fit using the same three-step model shown in Scheme 8, with the inclusion of a fourth step to describe the dissociation of $\mathbf{3}$ (Scheme $\mathrm{S}_{3}$ ). This fit is shown in Figure 10 and provides a rate constant for dissociation of $k_{4}=2.64 \pm 0.48$.

There are several examples of copper-catalyzed reactions that exhibit autocatalytic behavior such as polymerization, ${ }^{56}$ coupling $^{57,58}$ and cycloaddition ${ }^{52,59}$ reactions. Lei et $a l^{57}$ elegantly described $\mathrm{Cu}^{\mathrm{II}}-\mathrm{Cu}^{\mathrm{I}}$ cooperativity in the homocoupling of terminal alkynes with $\mathrm{Cu}^{\mathrm{II}}$. Biphenylacetylene, generated in situ, mediates the reduction of $\mathrm{CuCl}_{2}$ (TMEDA) with an accompanying induction period and autoacceleration curve. $\mathrm{Cu}^{\mathrm{I}}$ was confirmed as an autocatalyst, serving to reduce the induction period and enhance the reaction rate. Hartwig and coworkers have described the autocatalytic behavior of in situ generated $\mathrm{Cu}^{\mathrm{I}}$ in the reaction of well-defined $\mathrm{Cu}^{\mathrm{I}}$-amido complexes with iodoarenes..$^{58}$ Finally, Whitesides et al..$^{52}$ have reported on the autocatalytic behavior of the triazolyl product in the copper-catalyzed azide-alkyne cycloaddition (CuAAC) reaction between tripropargylamine and 2azidoethanol. In this example, the initial reduction of $\mathrm{Cu}^{\text {II }}$ to catalytically active $\mathrm{Cu}^{\mathrm{I}}$ is attributed to the terminal alkyne serving as a reducing agent, another well-accepted reactivity pattern throughout the literature..$^{52,61}$

We imagined that under our conditions, the catalysis by 3 (Scheme 8, Step 3) could occur by ligand exchange between complexes 3 and $\mathbf{5}$ to form the heteroleptic complex (phen) $\mathrm{Cu}^{\text {II }}\left(\mathrm{O}_{2} \mathrm{CC}_{6} \mathrm{H}_{4}-\mathrm{o}-\mathrm{NO}_{2}\right)(\mathrm{SPh})$ (Scheme 9, Step 1). This intermediate could react productively with $\mathrm{PhSSPh}$ to form product $\mathbf{1}$ and regenerate complex 3 (Scheme 9, Step 2). Thus, the overall reaction would be the formation of product 1 and complex 2 from 5 and $\mathrm{PhSSPh}$, catalyzed by complex $\mathbf{3}$ as shown in Scheme 8 (Step 3).

Scheme 9. Proposed Pathway for the Reaction of 5 with PhSSPh catalyzed by $3 .^{a}$

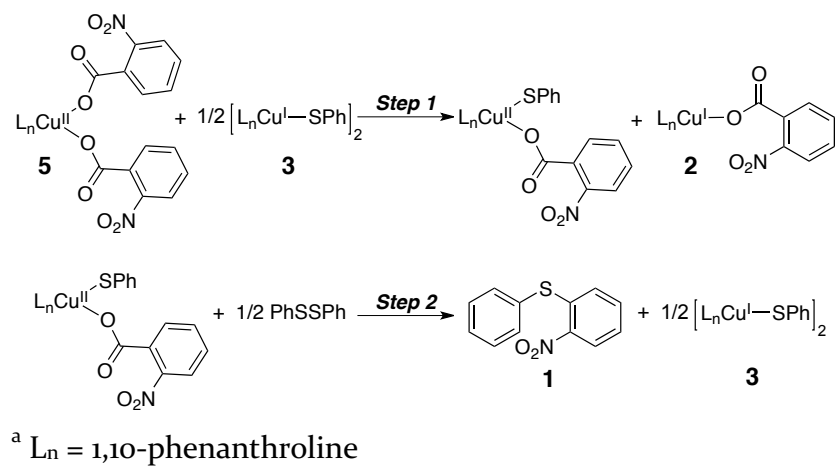

To explore the possible ligand exchange between complexes 3 and 5, we conducted the stoichiometric reaction of these two species under $\mathrm{N}_{2}$ at $140{ }^{\circ} \mathrm{C}$. Under these conditions, both product 1 and the 2,2'dinitrobiphenyl byproduct were formed in 35\% and $26 \%$ yields respectively. When the same reaction was performed under an $\mathrm{O}_{2}$ atmosphere, 1 was formed in $75 \%$ with no 2,2 '-dinitrobiphenyl detected. The formation of $\mathbf{1}$ from complexes $\mathbf{3}$ and $\mathbf{5}$ indicate facile ligand exchange under these conditions and support a ligand exchange step en route to product formation in the stoichiometric reactions of $\mathbf{5}$.

From the data described above, it is apparent that copper(II)-carboxylates can generate product $\mathbf{1}$ through a pathway that involves initial reduction to copper(I). More broadly, under our reaction conditions decarboxylation occurs from a $\mathrm{Cu}^{\mathrm{I}}$ species, and product formation occurs from subsequent reaction of the resulting $\mathrm{Cu}^{\mathrm{I}}$-(aryl) with $\mathrm{PhSSPh}$ as shown above. $\mathrm{Cu}^{\mathrm{II}}$ (carboxylate) species are not the catalytically relevant species but can access the same pathway either via decarboxylation (Scheme 7) or by ligand exchange in the presence of 3 (Scheme 9).

Aerobic Oxidation of Copper(I)-Thiolate. Owing to the formation of $\left[(\text { phen }) \mathrm{Cu}\left(\mu-\mathrm{SC}_{6} \mathrm{H}_{5}\right)\right]_{2}$ (3) in the stoichiometric reactions of complexes 2,4 , and 5 with $\mathrm{PhSSPh}$ under nitrogen, we decided to explore the reactivity of independently prepared 3 under catalytic conditions. For the reaction of 2-nitrobenzoic acid and $\mathrm{PhSH}$ with 3 as catalyst, in a sealed Schlenk tube equipped with an $\mathrm{O}_{2}$ balloon, 1 was obtained in $88 \%$ yield, demonstrating the catalytic competence of 3 .

We considered two likely pathways for the turnover of complex 3. First, we considered ligand exchange of 3 with benzoic acid or potassium 2-nitrobenzoate to generate complex 2 directly (Scheme 10, Pathway A). Alternatively, we considered a pathway in which $\mathrm{O}_{2}$ is required to facilitate the turnover of 3 (Scheme 10, Pathway B).

\section{Scheme 10. Possible pathways for the turnover of 3}

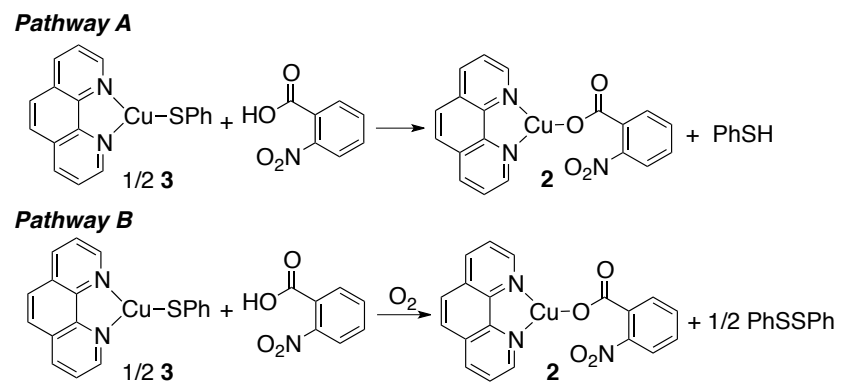

In pathway A, complex 3 would be expected to form product upon treatment with 2-nitrobenzoic acid under $\mathrm{N}_{2}$. In addition, the sole role of $\mathrm{O}_{2}$ in this manifold would be to generate $\mathrm{PhSSPh}$ from $\mathrm{PhSH}$, and catalytic turnover with $\mathrm{PhSSPh}$ would be expected to be efficient under anaerobic conditions. Such a pathway was 
ruled out based on a series of control experiments. The stoichiometric reaction of $\mathbf{3}$ and 2-nitrobenzoic acid was conducted under both $\mathrm{N}_{2}$ and $\mathrm{O}_{2}$ atmospheres. In the presence of $\mathrm{O}_{2}$, the sulfane product $\mathbf{1}$ is formed in $92 \%$ yield, while under $\mathrm{N}_{2}$ only $15 \%$ is obtained (Scheme 11). In addition, when the standard catalytic reaction of 2-nitrobenzoic acid and $\mathrm{PhSSPh}$ was conducted under $\mathrm{N}_{2}$, only a $15 \%$ yield of (2nitrophenyl)(phenyl)sulfane (1) was obtained, indicating an additional role for $\mathrm{O}_{2}$ in catalysis. These results are consistent with the quantitative formation of 3 in all stoichiometric reactions conducted under nitrogen, but it's absence under aerobic conditions (vide supra). We suspected that this species may be inert to turnover in the absence of $\mathrm{O}_{2}$ and thus requires $\mathrm{O}_{2}$ for catalysis. These data indicate a clear role for $\mathrm{O}_{2}$ in the activation of the copper(I)-thiolate dimer 3 as an entryway into catalysis, and are consistent with pathway B.

\section{Scheme 11. Stoichiometric Reaction of Complex 3} with 2-Nitrobenzoic Acid

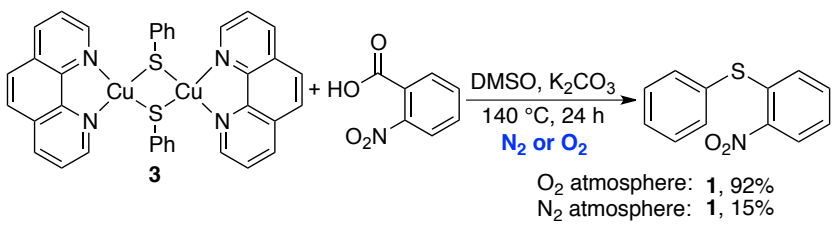

We therefore investigated the interaction of 3 with $\mathrm{O}_{2}$ by monitoring a solution of 3 in DMSO- $d_{6}$ under an $\mathrm{O}_{2}$ headspace at room temperature, by ${ }^{1} \mathrm{H}$ NMR spectroscopy. Complex 3 was observed to gradually generate $\mathrm{PhSSPh}$ in $71 \%$ conversion at room temperature after $2 \mathrm{~h}$ (Scheme 12). No diamagnetic copper species were observed, indicating the oxidation of $\mathrm{Cu}^{\mathrm{I}}$. Similarly, the color change from a deep-brown to a final green color accompanies this oxidation, consistent with the formation of a new oxidized copper(II) species, $\mathrm{Cu}_{\mathrm{ox}}$.

\section{Scheme 12. Aerobic oxidation of $[($ phen $) \mathrm{Cu}(\mu-$ $\left.\left.\mathrm{SC}_{6} \mathrm{H}_{5}\right)\right]_{2}(3)$ in DMSO-d 6}

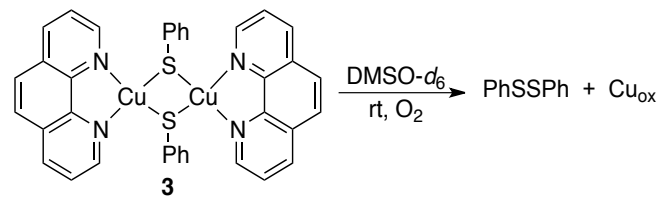

This aerobic oxidation of $\left[(\mathrm{phen}) \mathrm{Cu}\left(\mu-\mathrm{SC}_{6} \mathrm{H}_{5}\right)\right]_{2}(3)$ at $140{ }^{\circ} \mathrm{C}$ was also monitored by UV-visible spectroscopy. Complex 3 has characteristic bands at $441 \mathrm{~nm}$ attributed to a (phen) $\mathrm{Cu}^{\mathrm{I}}$ species and a shoulder at $\sim 538 \mathrm{~nm}$. A solution of 3 in DMSO was prepared in a septum-sealed cuvette equipped with a stir bar, in a $\mathrm{N}_{2}$ filled glovebox. On removal from the glovebox, an initial spectrum was taken after which an $\mathrm{O}_{2}$ balloon was inserted via the septum. The solution was heated with stirring at $140{ }^{\circ} \mathrm{C}$ in an aluminum block and the oxidation of $\mathrm{Cu}^{\mathrm{I}}$ was followed by monitoring the loss of the intense band shifted to $\sim 429 \mathrm{~nm}$ upon heating. The appearance of a new band of weak intensity between 711-722 $\mathrm{nm}$ attributed to (phen) ${ }_{2} \mathrm{Cu}^{\mathrm{II}}$ was also observed (Figure 11). An estimate of the rate of oxidation for an initial concentration of $\left[(\text { phen }) \mathrm{Cu}\left(\mu-\mathrm{SC}_{6} \mathrm{H}_{5}\right)\right]_{2}=0.17$ $\mathrm{mM}$ was $0.23 \mathrm{mM} \mathrm{h}^{-1}$.

Thus, we envisioned that under catalytic conditions, the aerobic oxidation of in situ generated 3 to liberate $\mathrm{PhSSPh}$ and catalytically relevant oxidized copper species, $\mathrm{Cu}_{\mathrm{ox}}$, is a key step in the process. The resulting $\mathrm{Cu}_{\text {ox }}$ regenerates $\mathbf{2}$ in the presence of carboxylate, as a path for re-entry into the cycle. We therefore explored the reactivity of in situ generated $\mathrm{Cu}_{\mathrm{ox}}$ in a series of NMR tube experiments. When a solution of 3 in DMSO- $d_{6}$ in a septum-sealed NMR tube was bubbled with $\mathrm{O}_{2}$ for several minutes and the resulting solution subsequently treated with 2-nitrobenzoic acid (3 equiv) in the presence of $\mathrm{K}_{2} \mathrm{CO}_{3}$ with heating at $140{ }^{\circ} \mathrm{C}$, (2-nitrophenyl)(phenyl)sulfane (1) was observed in $98 \%$ yield, after $4 \mathrm{~h}$. These results are indicative of the chemical competence of the $\mathrm{Cu}_{\mathrm{ox}}$ species resulting from the aerobic oxidation of 3 .

The importance of $\mathrm{O}_{2}$ for product formation has been observed in related aerobic $\mathrm{Cu}$-catalyzed thiolation reactions. Some of the more commonly proposed roles of $\mathrm{O}_{2}$ in these reactions include facilitating the conversion of thiol to disulfide, promoting the formation of organocopper thiolates, mediating $\mathrm{H}$-atom abstraction in $\mathrm{C}-\mathrm{H}$ substrates, oxidation of $\mathrm{Cu}(\mathrm{I})$-thiolates, suppressing undesired side reactions and facilitating the regeneration of catalytically active species. ${ }^{23,31,35}$ Based on our findings, however, in addition to facilitating the generation of RSSR from RSH, a key role of $\mathrm{O}_{2}$ in this system is to enable catalytic turnover via oxidative dissociation of an otherwise tightly bound thiolate ligand in $\left[(\text { phen }) \mathrm{Cu}\left(\mu-\mathrm{SC}_{6} \mathrm{H}_{5}\right)\right]_{2} \quad$ (3). This observation is consistent with findings of related aerobic coppercatalyzed thiolation reactions wherein dramatically reduced yields are observed in the absence of $\mathrm{O}_{2}$ thereby validating the importance of $\mathrm{O}_{2}$ in generating relevant competent species including catalytically active $\mathrm{Cu}$ species. ${ }^{110,25-27}$ 

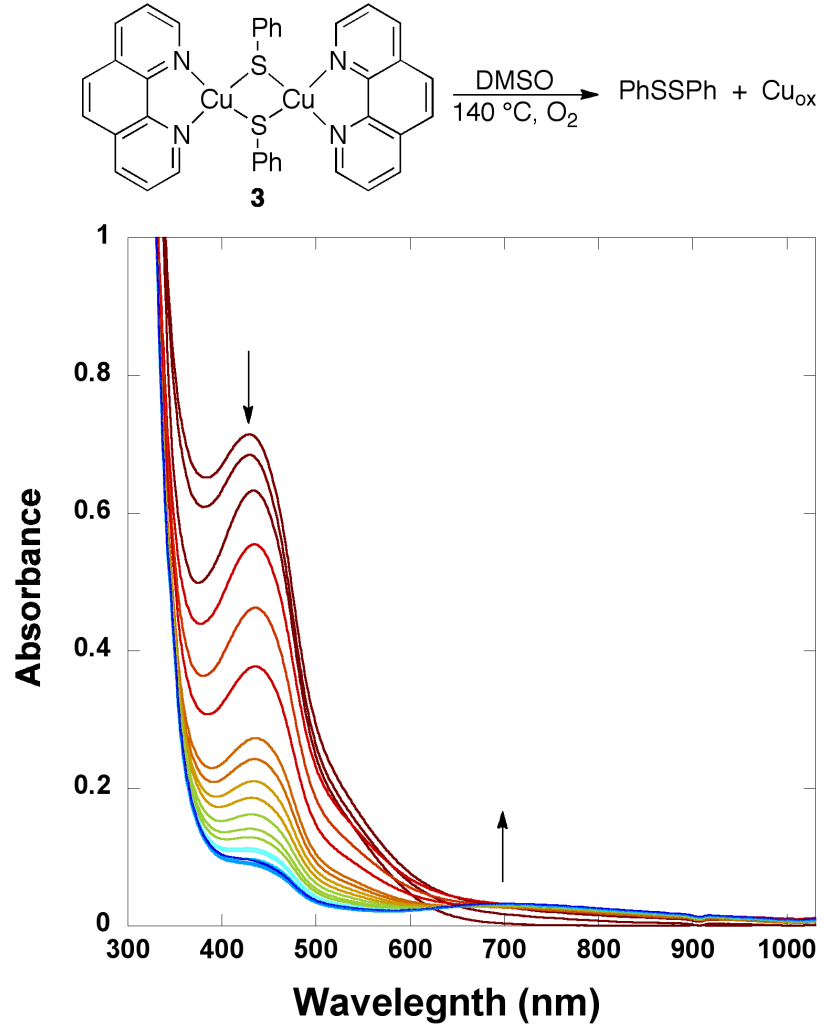

Figure 11. UV-visible spectra for the aerobic oxidation of $\left[(\text { phen }) \mathrm{Cu}\left(\mu-\mathrm{SC}_{6} \mathrm{H}_{5}\right)\right]_{2}(3)$ in DMSO at $140{ }^{\circ} \mathrm{C}$. Reaction conditions: $\left[(\text { phen }) \mathrm{Cu}\left(\mu-\mathrm{SC}_{6} \mathrm{H}_{5}\right)\right]_{2}(3)(0.2 \mathrm{mM})$, DMSO $(2.5 \mathrm{~mL})$, $\mathrm{O}_{2}$ balloon, $140{ }^{\circ} \mathrm{C}$.

Mechanistic Model. The above results reveal some key features of the mechanism of this aerobic copper catalyzed decarboxylative thiolation of benzoic acids. First, the rapid conversion of $\mathrm{PhSH}$ to $\mathrm{PhSSPh}$ under reaction conditions and the demonstrated chemical and kinetic competence of $\mathrm{PhSSPh}$ suggest $\mathrm{PhSSPh}$ is the active thiolating source. Secondly, all of the copper complexes synthesized in this study are competent catalysts for the reaction of 2-nitrobenzoic acid with $\mathrm{PhSH}$, and the observed generation of (phen) $\mathrm{Cu}\left(\mathrm{O}_{2} \mathrm{CC}_{6} \mathrm{H}_{4}-\mathrm{O}-\mathrm{NO}_{2}\right)$ (2) under $\mathrm{N}_{2}$ from reaction components strongly supports the intermediacy of this species under reaction conditions. Additionally, the spectroscopic data indicate a copper(I) resting state and the measured reaction orders exclude a turn-overlimiting step that is oxidation by $\mathrm{O}_{2}$ or reaction with $\mathrm{PhSSPh}$. Instead, decarboxylation of a copper(I)carboxylate is the most likely turn-over-limiting step of this reaction.

Mechanistic studies of copper-mediated redoxneutral decarboxylation reactions have shown these reactions to proceed through a pathway involving decarboxylation of a copper(I)-carboxylate. Under oxidative conditions, however, we expected that decarboxylation from a copper(II)-carboxylate intermediate may be plausible. Instead, our data indicate two pathways for the possible reduction of a copper(II)-carboxylate species to copper(I). In the absence of disulfide, a decarboxylative pathway enables reduction of copper with concomitant formation of the biaryl, while in the presence of disulfide, decarboxylative coupling forms 1 and copper(I). This pathway is evidenced by the dramatic difference in reaction profiles of the stoichiometric reactions of well-defined copper(I) and copper(II) carboxylate complexes. In particular, the reaction of copper(II) features an induction period and sigmoidal kinetics. This reaction behavior arises from the slow initial reaction of $\mathbf{5}$ with $\mathrm{PhSSPh}$, suggesting decarboxylation from a copper(I)-carboxylate to be operative under catalytic conditions.

$\mathrm{O}_{2}$ is essential for efficient product formation owing to the poor yields of the diarylsulfide (1) obtained in its absence. Although the oxidation of copper(I) species has been observed to be turn-over-limiting in a number of other copper-catalyzed aerobic reactions, ${ }^{64-}$ ${ }^{66}$ we believe that under our conditions the oxidation step is required in order to release a tightly bound thiolate ligand from 3, regenerating the active catalyst $\mathbf{2}$ in the presence of 2-nitrobenzoic acid and base. This was evidenced by the generation of $\mathrm{PhSSPh}$ upon the exposure of a solution of $\left[(\text { phen }) \mathrm{Cu}\left(\mu-\mathrm{SC}_{6} \mathrm{H}_{5}\right)\right]_{2}$ (3) in DMSO to $\mathrm{O}_{2}$ (Figure $\mathrm{S}_{5}$ ). The resultant in situ generated $\mathrm{Cu}_{\text {ox }}$ species was also chemically competent in producing (2-nitrophenyl)(phenyl)sulfane (1).

Inhibition of copper catalysis by a sulfur-based ligand has been observed in other systems, via the formation of the thermodynamically stable $\mathrm{Cu}$-SR bond. Liebeskind and coworkers ${ }^{65,66}$ have introduced a chelation-based dissociation strategy to re-activate the $\mathrm{Cu}$ catalyst in their $\mathrm{C}-\mathrm{C}$ coupling reactions. The generation of an active $\mathrm{Cu}$-oxygenate species from $\mathrm{Cu}-\mathrm{SR}$ under aerobic conditions was believed be a significant step in providing catalytic $\mathrm{Cu}$ for turnover. We believe that related oxidative dissociation pathways may be operative in a variety of $\mathrm{Cu}$-catalyzed aerobic thiolation reactions. ${ }^{25}$ 


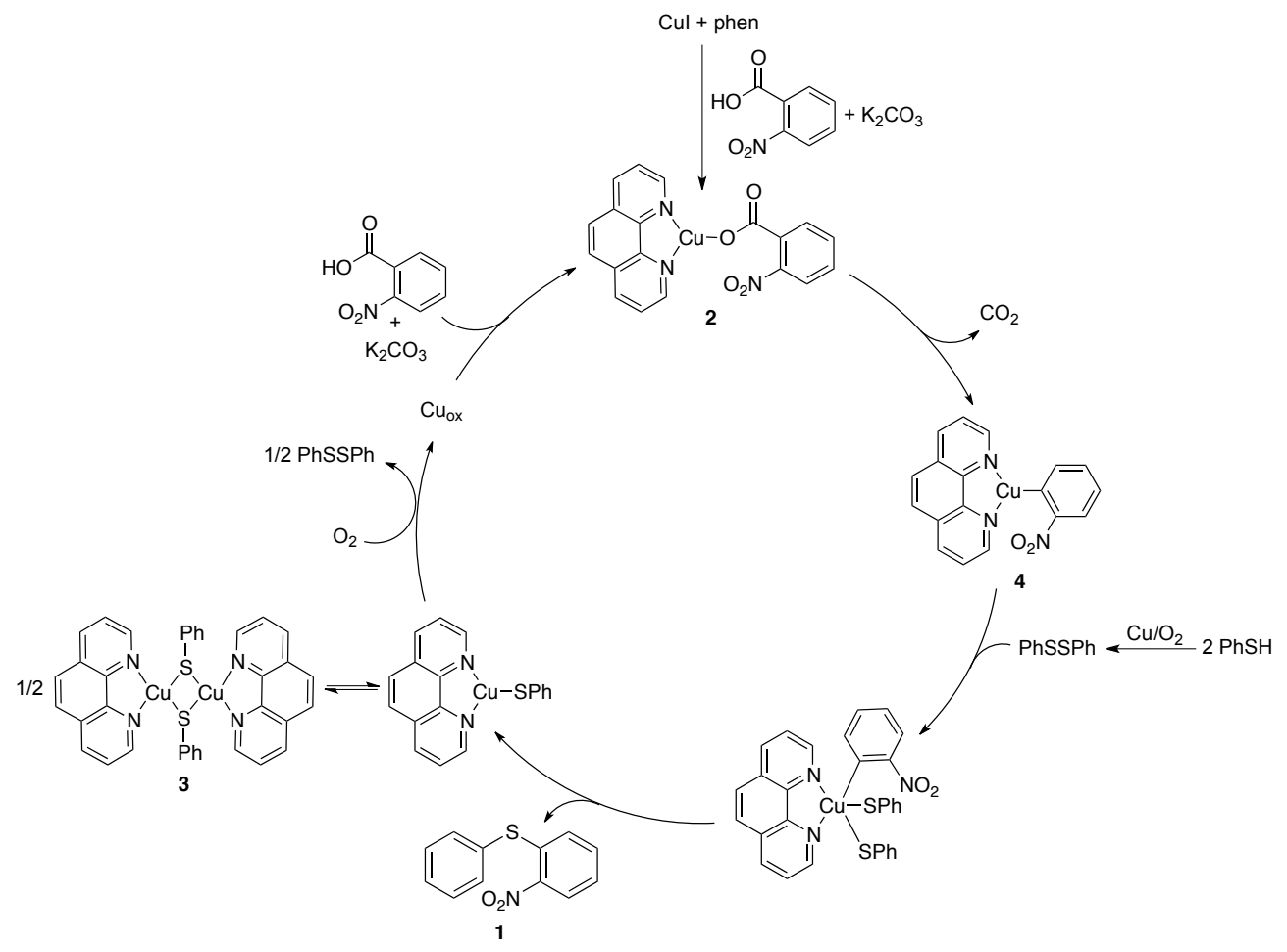

Scheme 13. Proposed mechanism of the aerobic Cu-catalyzed oxidative decarboxylative thiolation of benzoic acids.

Based on our findings we propose a reaction pathway (Scheme 13), that involves the generation and subsequent decarboxylation of 2 to form 4 . This decarboxylation precedes oxidative addition of the $\mathrm{PhSSPh}$ to the $\mathrm{Cu}^{\mathrm{I}}$-(aryl) 4, to generate a highly reactive organocopper(III)-dithiolate species that is well-poised for rapid reductive elimination to generate the diaryl sulfide product $\mathbf{1}$ and $\left[(\mathrm{phen}) \mathrm{Cu}\left(\mu-\mathrm{SC}_{6} \mathrm{H}_{5}\right)\right]_{2}$ (3). This latter step is supported by literature precedent involving well-defined macrocyclic organocopper(III) species and sulfur-based nucleophiles. ${ }^{30}$ The oxidative dissociation of 3 with $\mathrm{O}_{2}$ liberates $\mathrm{PhSSPh}$ and $\mathrm{Cu}_{\text {ox }}$ which regenerates 2 in the presence of 2-nitrobenzoic acid and $\mathrm{K}_{2} \mathrm{CO}_{3}$.

\section{CONCLUSIONS}

In summary, this work describes an experimental mechanistic study of the aerobic copper-catalyzed decarboxylative thiolation of benzoic acids. PhSSPh was found to be the active thiolating source under reaction conditions. Spectroscopic and kinetic studies suggest catalytically-relevant discrete (phen) $\mathrm{Cu}^{\mathrm{I}}$ complexes are chemically and kinetically competent in mediating product formation supporting their intermediacy. UV-visible studies strongly support a $\mathrm{Cu}^{\mathrm{l}}$ resting state. These findings provide valuable insight into key mechanistic steps for a phenanthroline-ligated $\mathrm{Cu}^{\mathrm{I}}$ catalyst system involved in the aerobic copper catalyzed C-S coupling reactions. Overall, the identification of the catalytic intermediates will allow for a more rational approach to the catalyst design and development process targeting catalytic systems capable of exploiting this observed mode of reactivity. The findings may also have implications for the improvement of related aerobic $\mathrm{Cu}$-mediated Cheteroatom bond formation reactions. ${ }^{6 a, 6 c}$

\section{ASSOCIATED CONTENT}

\section{Supporting Information.}

The Supporting Information is available free of charge

Experimental procedures, kinetic data, spectral data (PDF)

\section{AUTHOR INFORMATION}

Corresponding Author

*E-mail: Jessica.Hoover@mail.wvu.edu

\section{ACKNOWLEDEGMENTS}

We are grateful to the NSF (CHE-1454879) and West Virginia University for financial support of this work. NMR spectroscopy facilities were partially supported by the NSF (CHE-1228336). We thank Donna Blackmond for helpful discussions of reaction kinetics. 


\section{REFERENCES}

(1) (a) Bhunia, S.; Pawar, G. G.; Kumar, S. V.; Jiang, Y.; Ma, D., Selected Copper-Based Reactions for C-N, C-O, C-S, and C-C Bond Formation. Angew. Chem. Int. Ed. 2017, 56, 16136-16179; (b) Sambiagio, C.; Marsden, S. P.; Blacker, A. J.; McGowan, P. C., Copper catalysed Ullmann type chemistry: from mechanistic aspects to modern development. Chem. Soc. Rev. 2014, 43, 35253550; (c) Guo, X.-X.; Gu, D.-W.; Wu, Z.; Zhang, W., CopperCatalyzed $\mathrm{C}-\mathrm{H}$ Functionalization Reactions: Efficient Synthesis of Heterocycles. Chem. Rev. 2015, 115, 1622-1651.

(2) (a) Perry, G. J. P.; Larrosa, I., Recent Progress in Decarboxylative Oxidative Cross-Coupling for Biaryl Synthesis. Eur. J. Org. Chem. 2017, 2017, 3517-3527. (b) Rodríguez, N.; Goossen, L. J., Decarboxylative coupling reactions: a modern strategy for C-Cbond formation. Chem. Soc. Rev. 2011, 40, 5030-5048.

(3) (a) Bhadra, S.; Dzik, W. I.; Goossen, L. J., Decarboxylative Etherification of Aromatic Carboxylic Acids. J. Am. Chem. Soc. 2012, 134, 9938-9941. (b) Hoover, J. M., Mechanistic Aspects of Copper-Catalyzed Decarboxylative Coupling Reactions of (Hetero)Aryl Carboxylic Acids. Comments Inorg. Chem. 2017, 37, 169200.

(4) (a) Baur, A.; Bustin, K. A.; Aguilera, E.; Petersen, J. L.; Hoover, J. M., Copper and silver benzoate and aryl complexes and their implications for oxidative decarboxylative coupling reactions. Org. Chem. Front. 2017, 4, 519-524. (b) Song, Q.; Feng, Q.; Zhou, M., Copper-Catalyzed Oxidative Decarboxylative Arylation of Benzothiazoles with Phenylacetic Acids and $\alpha-$ Hydroxyphenylacetic Acids with $\mathrm{O}_{2}$ as the Sole Oxidant. Org. Lett. 2013, 15, 5990-5993. (c) Moon, P. J.; Fahandej-Sadi, A.; Qian, W.; Lundgren, R. J., Decarboxylative Benzylation of Aryl and Alkenyl Boronic Esters. Angew. Chem. Int. Ed. 2018, 57, 46124616. (d) Patra, T.; Nandi, S.; Sahoo, S. K.; Maiti, D., Copper mediated decarboxylative direct $\mathrm{C}-\mathrm{H}$ arylation of heteroarenes with benzoic acids. Chem. Commun. 2016, 52, 1432-1435.

(5) (a) Tang, J.; Biafora, A.; Goossen, L. J., Catalytic Decarboxylative Cross-Coupling of Aryl Chlorides and Benzoates without Activating ortho Substituents. Angew. Chem. Int. Ed. 2015, 54, 13130-13133. (b) Li, T.; Sun, P.; Yang, H.; Zhu, Y.; Yan, H.; Lu, L.; Mao, J., Copper-catalyzed decarboxylative coupling of aryl halides with alkynyl carboxylic acids performed in water. Tetrahedron. 2012, 68, 6413-6419. (c) Shang, R.; Fu, Y.; Wang, Y.; Xu, Q.; Yu, H.-Z.; Liu, L., Copper-Catalyzed Decarboxylative CrossCoupling of Potassium Polyfluorobenzoates with Aryl Iodides and Bromides. Angew. Chem. Int. Ed. 2009, 48, 9350-9354. (d) Qu, X.; Li, T.; Sun, P.; Zhu, Y.; Yang, H.; Mao, J., Highly effective copper-catalyzed decarboxylative coupling of aryl halides with alkynyl carboxylic acids. Org. Biomol. Chem. 2011, 9, 6938-6942. (e) Gooßen, L. J.; Deng, G.; Levy, L. M., Synthesis of Biaryls via Catalytic Decarboxylative Coupling. Science. 20o6, 313, 662-664.

(6) (a) Zhang, Y.; Patel, S.; Mainolfi, N., Copper-catalyzed decarboxylative $\mathrm{C}-\mathrm{N}$ coupling for $\mathrm{N}$-arylation. Chem. Sci. 2012, 3, 3196-3199. (b) Jia, W.; Jiao, N., Cu-Catalyzed Oxidative Amidation of Propiolic Acids Under Air via Decarboxylative Coupling. Org. Lett. 2010, 12, 2000-2003. (c) Pichette Drapeau, M.; Bahri, J.; Lichte, D.; Gooßen, L. J., Decarboxylative ipso Amination of Activated Benzoic Acids. Angew. Chem. Int. Ed. 2019, 58 , 892-896.

(7) (a) Liang, Y.; Zhang, X.; MacMillan, D. W. C., Decarboxylative $\mathrm{sp}^{3} \mathrm{C}-\mathrm{N}$ coupling via dual copper and photoredox catalysis. Nature. 2018, 559, 83-88. (b) Liu, Z.-J.; Lu, X.; Wang, G.; Li, L.; Jiang, W.-T.; Wang, Y.-D.; Xiao, B.; Fu, Y., Directing Group in Decarboxylative Cross-Coupling: Copper-Catalyzed SiteSelective C-N Bond Formation from Nonactivated Aliphatic Carboxylic Acids. J. Am. Chem. Soc. 2016, 138, 9714-9719. (c)
Zhao, W.; Wurz, R. P.; Peters, J. C.; Fu, G. C., Photoinduced, Copper-Catalyzed Decarboxylative $\mathrm{C}-\mathrm{N}$ Coupling to Generate Protected Amines: An Alternative to the Curtius Rearrangement. J. Am. Chem. Soc. 2017, 139, 12153-12156.

(8) Shen, C.; Zhang, P.; Sun, Q.; Bai, S.; Hor, T. S. A.; Liu, X., Recent advances in $\mathrm{C}-\mathrm{S}$ bond formation via $\mathrm{C}-\mathrm{H}$ bond functionalization and decarboxylation. Chem. Soc. Rev. 2015, 44, 291-314.

(9) (a) Alcaraz, M.-L.; Atkinson, S.; Cornwall, P.; Foster, A. C.; Gill, D. M.; Humphries, L. A.; Keegan, P. S.; Kemp, R.; Merifield, E.; Nixon, R. A.; Noble, A. J.; O'Beirne, D.; Patel, Z. M.; Perkins, J.; Rowan, P.; Sadler, P.; Singleton, J. T.; Tornos, J.; Watts, A. J.; Woodland, I. A., Efficient Syntheses of AZD4407 via Thioether Formation by Nucleophilic Attack of Organometallic Species on Sulphur. Org. Process Res. Dev. 2005, 9, 555-569. (b) Feng, M.; Tang, B.; Liang, S. H.; Jianga, X., Sulfur Containing Scaffolds in Drugs: Synthesis and Application in Medicinal Chemistry. Curr. Top. Med. Chem. 2016, 16, 1200-1216. (c) Hirate, K.; Uchida, A.; Ogawa, Y.; Arai, T.; Yoda, K., Zaltoprofen, a non-steroidal antiinflammatory drug, inhibits bradykinin-induced pain responses without blocking bradykinin receptors. Neurosci. Res. 2006, 54, 288-294.

(10) Li, M.; Hoover, J. M., Aerobic copper-catalyzed decarboxylative thiolation. Chem. Commun. 2016, 52, 8733-8736.

(11) (a) Hu, L.; Wang, D.; Chen, X.; Yu, L.; Yu, Y.; Tan, Z.; Zhu, G., Copper-catalyzed decarboxylative methylthiolation of aromatic carboxylate salts with DMSO. Org. Biomol. Chem. 2017, 15, 5674-5679. (b) Rong, G.; Mao, J.; Liu, D.; Yan, H.; Zheng, Y.; Chen, J., Formation of $\mathrm{C}\left(\mathrm{sp}^{2}\right)-\mathrm{S}$ bonds through decarboxylation of $\alpha$-oxocarboxylic acids with disulfides or thiophenols. RSC $A d v$. 2015, 5, 26461-26464. (c) Duan, Z.; Ranjit, S.; Zhang, P.; Liu, X., Synthesis of Aryl Sulfides by Decarboxylative C-S CrossCouplings. Chem. Eur. J. 2009, 15, 3666-3669. (d) Ranjit, S.; Duan, Z.; Zhang, P.; Liu, X., Synthesis of Vinyl Sulfides by Copper-Catalyzed Decarboxylative C-S Cross-Coupling. Org. Lett. 2010, 12, 4134-4136.

(12) Li, X.; Yang, F.; Wu, Y.; Wu, Y., Copper-Mediated Oxidative Decarboxylative Coupling of Arylpropiolic Acids with Dialkyl H-Phosphonates in Water. Org. Lett. 2014, 16, 992-995.

(13) (a) Allen, S. E.; Walvoord, R. R.; Padilla-Salinas, R.; Kozlowski, M. C., Aerobic Copper-Catalyzed Organic Reactions. Chem. Rev. 2013, 113, 6234-6458. (b) McCann, S. D.; Stahl, S. S., Copper-Catalyzed Aerobic Oxidations of Organic Molecules: Pathways for Two-Electron Oxidation with a Four-Electron Oxidant and a One-Electron Redox-Active Catalyst. Acc. Chem. Res. 2015, 48, 1756-1766. (c) Wendlandt, A. E.; Suess, A. M.; Stahl, S. S., Copper-Catalyzed Aerobic Oxidative C-H Functionalizations: Trends and Mechanistic Insights. Angew. Chem. Int. Ed. 2011, 50, 11062-11087.

(14) Ueda, S.; Nagasawa, H., Synthesis of 2-Arylbenzoxazoles by Copper-Catalyzed Intramolecular Oxidative C-O Coupling of Benzanilides. Angew. Chem. Int. Ed. 2008, 47, 6411-6413.

(15) (a) Do, H.-Q.; Daugulis, O., An Aromatic Glaser-Hay Reaction. J. Am. Chem. Soc. 2009, 131, 17052-17053. (b) Roane, J.; Daugulis, O., Copper-Catalyzed Etherification of Arene $\mathrm{C}-\mathrm{H}$ Bonds. Org. Lett. 2013, 15, 5842-5845. (c) Roane, J.; Daugulis, O., A General Method for Aminoquinoline-Directed, CopperCatalyzed sp ${ }^{2}$ C-H Bond Amination. J. Am. Chem. Soc. 2016, 138, 4601-4607.

(16) Miura, W.; Hirano, K.; Miura, M., Copper-Mediated Oxidative Coupling of Benzamides with Maleimides via Directed CH Cleavage. Org. Lett. 2015, 17, 4034-4037.

(17) Chen, X.; Hao, X.-S.; Goodhue, C. E.; Yu, J.-Q., Cu(II)Catalyzed Functionalizations of Aryl C-H Bonds Using $\mathrm{O}_{2}$ as an Oxidant. J. Am. Chem. Soc. 20o6, 128, 6790-6791. 
(18) (a) Chen, L.; Ju, L.; Bustin, K. A.; Hoover, J. M., Coppercatalyzed oxidative decarboxylative $\mathrm{C}-\mathrm{H}$ arylation of benzoxazoles with 2-nitrobenzoic acids. Chem. Commun. 2015, 51, 1505915062. (b) Dai, J.-J.; Liu, J.-H.; Luo, D.-F.; Liu, L., Pd-catalysed decarboxylative Suzuki reactions and orthogonal $\mathrm{Cu}$-based $\mathrm{O}-$ arylation of aromatic carboxylic acids. Chem. Commun. 2011, 47, 677-679.

(19) (a) Crawford, J. M.; Shelton, K. E.; Reeves, E. K.; Sadarananda, B. K.; Kalyani, D., Nickel-Catalyzed Decarboxylative Arylation of Azoles with Perfluoro- and Nitrobenzoates. Org. Chem. Front. 2015, 46, (38), 726-729. (b) Honeycutt, A. P.; Hoover, J. M., Nickel-Catalyzed Oxidative Decarboxylative (Hetero)Arylation of Unactivated $\mathrm{C}-\mathrm{H}$ Bonds: $\mathrm{Ni}$ and $\mathrm{Ag}$ Synergy. ACS Catal. 2017, 7, 4597-46o1. (c) Tanaka, D.; Romeril, S. P.; Myers, A. G., On the Mechanism of the Palladium(II)-Catalyzed Decarboxylative Olefination of Arene Carboxylic Acids. Crystallographic Characterization of Non-Phosphine Palladium(II) Intermediates and Observation of Their Stepwise Transformation in Heck-like Processes. J. Am. Chem. Soc. 2005, 127, 10323-10333.

(20) (a) Myers, A. G.; Tanaka, D.; Mannion, M. R., Development of a Decarboxylative Palladation Reaction and Its Use in a Heck-type Olefination of Arene Carboxylates. J. Am. Chem. Soc. 2002, 124, 11250-11251. (b) Feng, C.; Loh, T.-P., Palladiumcatalyzed decarboxylative cross-coupling of alkynyl carboxylic acids with arylboronic acids. Chem. Commun. 2010, 46, 47794781. (c) Cornella, J.; Lahlali, H.; Larrosa, I., Decarboxylative homocoupling of (hetero)aromatic carboxylic acids. Chem. Commun. 2010, 46, 8276-8278. (d) Cornella, J.; Lu, P.; Larrosa, I., Intermolecular Decarboxylative Direct C-3 Arylation of Indoles with Benzoic Acids. Org. Lett. 2009, 11, 5506-5509.

(21) Gooßen, L. J.; Rodríguez, N.; Linder, C.; Lange, P. P.; Fromm, A., Comparative Study of Copper- and Silver-Catalyzed Protodecarboxylations of Carboxylic Acids. ChemCatChem. 2010, 2, 430-442.

(22) Cohen, T.; Berninger, R. W.; Wood, J. T., Products and kinetics of decarboxylation of activated and unactivated aromatic cuprous carboxylates in pyridine and in quinoline. J. Org. Chem. 1978, 43, 837-848.

(23) Fromm, A.; van Wüllen, C.; Hackenberger, D.; Gooßen, L. J., Mechanism of $\mathrm{Cu} / \mathrm{Pd}$-Catalyzed Decarboxylative CrossCouplings: A DFT Investigation. J. Am. Chem. Soc. 2014, 136, 10007-10023.

(24) Xue, L.; Su, W.; Lin, Z., Mechanism of silver- and coppercatalyzed decarboxylation reactions of aryl carboxylic acids. Dalton Trans. 2011, 40, 11926-11936.

(25) (a) Taniguchi, N., Aryl or Alkylation of Diaryl Disulfides Using Organoboronic Acids and a Copper Catalyst. Synlett. 2006, 37, 1351-1354. (b) . Fukuzawa, S.-i.; Shimizu, E.; Atsuumi, Y.; Haga, M.; Ogata, K., Copper-catalyzed direct thiolation of benzoxazole with diaryl disulfides and aryl thiols. Tetrahedron Lett. 2009, 50 (20), 2374-2376.

(26) Zhang, S.; Qian, P.; Zhang, M.; Hu, M.; Cheng, J., CopperCatalyzed Thiolation of the Di- or Trimethoxybenzene Arene C-H Bond with Disulfides. J. Org. Chem. 2010, 75 (19), 6732-6735.

(27) Yu, C.; Zhang, C.; Shi, X., Copper-Catalyzed Direct Thiolation of Pentafluorobenzene with Diaryl Disulfides or Aryl Thiols by $\mathrm{C}-\mathrm{H}$ and $\mathrm{C}-\mathrm{F}$ Bond Activation. Eur. J. Org. Chem. 2012, 2012, 1953-1959.

(28) Yin, X.; Jiang, Y.; Chu, S.; Ma, G.; Yin, Q.; Fang, X.; Pan, Y., Insight into copper-catalyzed decarboxylative thiolation of carboxylic acids in the gas phase. Tetrahedron. 2018, 74, 29212924.
(29) Chen, C.; Weng, Z.; Hartwig, J. F., Synthesis of Copper(I) Thiolate Complexes in the Thioetherification of Aryl Halides. Organometallics. 2012, 31, 8031-8037.

(30) (a) Font, M.; Parella, T.; Costas, M.; Ribas, X., Catalytic C$\mathrm{S}, \mathrm{C}-\mathrm{Se}$, and C-P Cross-Coupling Reactions Mediated by a CuI/CuIII Redox Cycle. Organometallics. 2012, 31, 7976-7982. (b) Huffman, L. M.; Stahl, S. S., Carbon-Nitrogen Bond Formation Involving Well-Defined Aryl-Copper(III) Complexes. J. Am. Chem. Soc. 2oo8, 130, 9196-9197. (c) Yao, B.; Wang, D.-X.; Huang, Z.-T.; Wang, M.-X., Room-temperature aerobic formation of a stable aryl-Cu(III) complex and its reactions with nucleophiles: highly efficient and diverse arene $\mathrm{C}-\mathrm{H}$ functionalizations of azacalix[1]arene[3]pyridine. Chem. Commun. 2009, 2899-2901.

(31) Ranjit, S.; Lee, R.; Heryadi, D.; Shen, C.; Wu, J. E.; Zhang, P.; Huang, K.-W.; Liu, X., Copper-Mediated C-H Activation/C-S Cross-Coupling of Heterocycles with Thiols. J. Org. Chem. 2011, 76, 8999-9007.

(32) Castanheiro, T.; Gulea, M.; Donnard, M.; Suffert, J., Practical Access to Aromatic Thiocyanates by CuCN-Mediated Direct Aerobic Oxidative Cyanation of Thiophenols and Diaryl Disulfides. Eur. J. Org. Chem. 2014, 2014, 7814-7817

(33) Tran, L. D.; Popov, I.; Daugulis, O., Copper-Promoted Sulfenylation of sp2 C-H Bonds. J. Am. Chem. Soc. 2012, 134, 1823718240.

(34) (a) Smith, R. C.; Reed, V. D.; Hill, W. E., Oxidation Of Thiols By Copper(II). Phosphorus, Sulfur Silicon Relat. Elem. 1994, 90, 147-154. (b) Kuijpers, F. P. J. Oxidation of thiols by oxygen catalysed by copper(II)ions or vitamin B12. Technische Hogeschool Eindhoven, Eindhoven, 1974.

(35) Xu, H.-J.; Zhao, Y.-Q.; Feng, T.; Feng, Y.-S., Chan-LamType S-Arylation of Thiols with Boronic Acids at Room Temperature. J. Org. Chem. 2012, 77, 2878-2884.

(36) (a) Tye, J. W.; Weng, Z.; Johns, A. M.; Incarvito, C. D.; Hartwig, J. F., Copper complexes of anionic nitrogen ligands in the amidation and imidation of aryl halides. J. Am. Chem. Soc. 2008, 130, 9971-9983. (b) Tye, J. W.; Weng, Z.; Giri, R.; Hartwig, J. F., Copper(I) phenoxide complexes in the etherification of aryl halides. Angew. Chem. Int. Ed. Engl. 2010, 49, 2185-2189. (c) Kaeser, A.; Mohankumar, M.; Mohanraj, J.; Monti, F.; Holler, M.; Cid, J.-J.; Moudam, O.; Nierengarten, I.; Karmazin-Brelot, L.; Duhayon, C.; Delavaux-Nicot, B.; Armaroli, N.; Nierengarten, J.F., Heteroleptic Copper(I) Complexes Prepared from Phenanthroline and Bis-Phosphine Ligands. Inorg. Chem. 2013, 52, 1214012151.

(37) (a) Franc, G.; Jutand, A., On the origin of copper(I) catalysts from copper(II) precursors in $\mathrm{C}-\mathrm{N}$ and $\mathrm{C}-\mathrm{O}$ crosscouplings. Dalton Trans. 2o10, 39, 7873-7875. (b) Soria-Castro, S. M.; Andrada, D. M.; Caminos, D. A.; Argüello, J. E.; Robert, M.; Peñéñory, A. B., Mechanistic Insight into the $\mathrm{Cu}$-Catalyzed $\mathrm{C}-\mathrm{S}$ Cross-Coupling of Thioacetate with Aryl Halides: A Joint Experimental-Computational Study. J. Org. Chem. 2o17, 82, 1146411473. (c) Zhang, S.-L.; Fan, H.-J. Theoretical Study on CopperCatalyzed S-Arylation of Thiophenols with Aryl Halides: Evidence Supporting the $\mathrm{LCu}(\mathrm{I})-\mathrm{SPh}$ Active Catalyst and Halogen Atom Transfer Mechanism. Organometallics 2o13, 32, 4944-4951.

(38) Ording-Wenker, E. C. M.; Siegler, M. A.; Bouwman, E., Coordination of new disulfide ligands to $\mathrm{Cu}^{\mathrm{I}}$ and $\mathrm{Cu}^{\mathrm{II}}$ : Does a $\mathrm{Cu}^{\mathrm{II}} \mu$-thiolate complex form? Inorg. Chim. Acta. 2015, 428, 193202.

(39) Cohen, T.; Schambach, R. A., Copper-quinoline decarboxylation. J. Am. Chem. Soc. 1970, 92, 3189-3190.

(40) Chodowska-Palicka, J.; Nilsson, M., Decarboxylation of 2Nitrobenzoic Acids. Acta Chem. Scand. 1970, 24, 3353-3361. 
(41) Cairncross, A.; Roland, J. R.; Henderson, R. M.; Sheppard, W. A., Organocopper intermediates via decarboxylation of cuprous carboxylates. J. Am. Chem. Soc. 1970, 92, 3187-3189.

(42) Gooßen, L. J.; Thiel, W. R.; Rodríguez, N.; Linder, C.; Melzer, B., Copper-Catalyzed Protodecarboxylation of Aromatic Carboxylic Acids. Adv. Synth. Catal. 2007, 349, 2241-2246.

(43) Srogl, J.; Hývl, J.; Révész, Á.; Schröder, D., Mechanistic insights into a copper-disulfide interaction in oxidation of imines by disulfides. Chem. Commun. 2009, 3463-3465.

(44) (a) Beurskens, P. T.; Cras, J. A.; Steggerda, J. J., Structure and properties of dibromo-N,N-dibutyldithiocarbamato complexes of copper(III) and gold(III). Inorg. Chem. 1968, 7, 810-813. (b) Willert-Porada, M. A.; Burton, D. J.; Baenziger, N. C., Synthesis and X-ray structure of bis(trifluoromethyl) $(\mathrm{N}, \mathrm{N}-$ diethyldithiocarbamato)-copper; a remarkably stable perfluoroalkylcopper(III) complex. J. Chem. Soc., Chem. Commun. 1989, 1633-1634.

(45) Savarin, C.; Srogl, J.; Liebeskind, L. S., A Mild, Nonbasic Synthesis of Thioethers. The Copper-Catalyzed Coupling of Boronic Acids with $\mathrm{N}-\mathrm{Thio}($ alkyl, aryl, heteroaryl)imides. Org. Lett. 2002, 4, 4309-4312.

(46) Gandeepan, P.; Koeller, J.; Ackermann, L., Expedient C-H Chalcogenation of Indolines and Indoles by Positional-Selective Copper Catalysis. ACS Catal. 2017, 7, 1030-1034.

(47) Wang, J.; Li, H.; Leng, T.; Liu, M.; Ding, J.; Huang, X.; Wu, H.; Gao, W.; Wu, G., Copper-catalyzed ipso-selenation of aromatic carboxylic acids. Org. Biomol. Chem. 2017, 15, 9718-9726.

(48) (a) Paine, A. J., Mechanisms and models for copper mediated nucleophilic aromatic substitution. 2. Single catalytic species from three different oxidation states of copper in an Ullmann synthesis of triarylamines. J. Am. Chem. Soc. 1987, 109, 1496-1502. (b) Yi, H.; Zhang, G.; Xin, J.; Deng, Y.; Miller, J. T.; Kropf, A. J.; Bunel, E. E.; Qi, X.; Lan, Y.; Lee, J.-F.; Lei, A., Homolytic cleavage of the $\mathrm{O}-\mathrm{Cu}(\mathrm{II})$ bond: XAFS and EPR spectroscopy evidence for one electron reduction of $\mathrm{Cu}(\mathrm{II})$ to $\mathrm{Cu}(\mathrm{I})$. Chem. Commun. 2016, 52, 6914-6917. (c) Aalten, H. L.; van Koten, G.; Grove, D. M.; Kuilman, T.; Piekstra, O. G.; Hulshof, L. A.; Sheldon, R. A., The copper catalysed reaction of sodium methoxide with aryl bromides. A mechanistic study leading to a facile synthesis of anisole derivatives. Tetrahedron 1989, 45, 5565-5578.

(49) Barreca, D.; Fois, E.; Gasparotto, A.; Seraglia, R.; Tondello, E.; Tabacchi, G., How Does $\mathrm{Cu}^{\text {II }}$ Convert into $\mathrm{Cu}^{\mathrm{I}}$ ? An Unexpected Ring-Mediated Single-Electron Reduction. Chem. Eur. J. 2011, 17, 10864-10870.

(50) Sperotto, E.; van Klink, G. P. M.; van Koten, G.; de Vries, J. G., The mechanism of the modified Ullmann reaction. Dalton Trans. 2010, 39, 10338-10351.

(51) Weingarten, H., Mechanism of the Ullmann Condensation. J. Org. Chem. 1964, 29, 3624-3626.

(52) Semenov, S. N.; Belding, L.; Cafferty, B. J.; Mousavi, M. P. S.; Finogenova, A. M.; Cruz, R. S.; Skorb, E. V.; Whitesides, G. M., Autocatalytic Cycles in a Copper-Catalyzed Azide-Alkyne $\mathrm{Cy}$ cloaddition Reaction. J. Am. Chem. Soc. 2018, 140, 10221-10232.

(53) Mower, M. P.; Blackmond, D. G., Mechanistic Rationalization of Unusual Sigmoidal Kinetic Profiles in the Machetti-De Sarlo Cycloaddition Reaction. J. Am. Chem. Soc. 2015, 137, 23862391.

(54) Hoops, S.; Sahle, S.; Gauges, R.; Lee, C.; Pahle, J.; Simus, N.; Singhal, M.; Xu, L.; Mendes, P.; Kummer, U., COPASI-a COmplex PAthway SImulator. Bioinformatics 2006, 22, 30673074 .

(55) Burés, J., A Simple Graphical Method to Determine the Order in Catalyst. Angew. Chem. Int. Ed. 2016, 55, 2028-2031.
(56) Gao, Y.; Zhao, T.; Zhou, D.; Greiser, U.; Wang, W., Insights into Relevant Mechanistic Aspects about the Induction

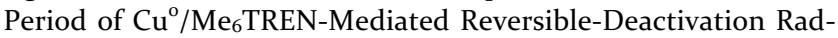
ical Polymerization. Chem. Commun. 2o15, 51, 14435-14438.

(57) Bai, R.; Zhang, G.; Yi, H.; Huang, Z.; Qi, X.; Liu, C.; Miller, J. T.; Kropf, A. J.; Bunel, E. E.; Lan, Y.; Lei, A., Cu(II)-Cu(I) Synergistic Cooperation to Lead the Alkyne C-H Activation. J. Am. Chem. Soc. 2014, 136, 16760-16763.

(58) Giri, R.; Hartwig, J. F., Cu(I)-Amido Complexes in the Ullmann Reaction: Reactions of $\mathrm{Cu}(\mathrm{I})$-Amido Complexes with Iodoarenes with and without Autocatalysis by CuI. J. Am. Chem. Soc. 2010, 132, 15860-15863.

(59) Chan, T. R.; Hilgraf, R.; Sharpless, K. B.; Fokin, V. V., Polytriazoles as Copper(I)-Stabilizing Ligands in Catalysis. Org. Lett. 2004, 6, 2853-2855.

(6o) Döhler, D.; Michael, P.; Binder, W. H., Autocatalysis in the Room Temperature Copper(I)-Catalyzed Alkyne-Azide "Click" Cycloaddition of Multivalent Poly(acrylate)s and Poly(isobutylene)s. Macromolecules 2012, 45, 3335-3345.

(61) Zhang, G.; Yi, H.; Zhang, G.; Deng, Y.; Bai, R.; Zhang, H.; Miller, J. T.; Kropf, A. J.; Bunel, E. E.; Lei, A., Direct Observation of Reduction of $\mathrm{Cu}(\mathrm{II})$ to $\mathrm{Cu}(\mathrm{I})$ by Terminal Alkynes. J. Am. Chem. Soc. 2014, 136, 924-926.

(62) Hoover, J. M.; Ryland, B. L.; Stahl, S. S., Mechanism of Copper(I)/TEMPO-Catalyzed Aerobic Alcohol Oxidation. J. Am. Chem. Soc. 2013, 135, 2357-2367.

(63) Price, C. C.; Nakaoka, K., Some Studies of Oxidative Coupling of Phenols. Macromolecules 1971, 4, 363-369.

(64) Hewgley, J. B.; Stahl, S. S.; Kozlowski, M. C., Mechanistic Study of Asymmetric Oxidative Biaryl Coupling: Evidence for Self-Processing of the Copper Catalyst to Achieve Control of Oxidase vs Oxygenase Activity. J. Am. Chem. Soc. 2008, 130, 12232-12233.

(65) Villalobos, J. M.; Srogl, J.; Liebeskind, L. S., A New Paradigm for Carbon-Carbon Bond Formation: Aerobic, CopperTemplated Cross-Coupling. J. Am. Chem. Soc. 2007, 129, 1573415735 .

(66) Varela-Álvarez, A.; Liebeskind, L. S.; Musaev, D. G., Mechanistic Insights into the Aerobic Copper(I)-Catalyzed Cross-Coupling of S-Acyl Thiosalicylamide Thiol Esters and Boronic Acids. Organometallics 2012, 31, 7958-7968. 
SYNOPSIS TOC

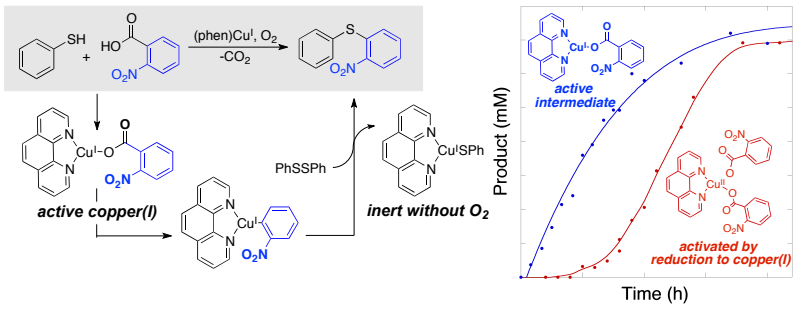

